\title{
I. MEZQUITA DE CÓRDOBA. TRAZADO PROPORCIONAL DE SU PLANTA GENERAL $\left(\right.$ SIGLOS VIII-X) ${ }^{1}$
}

\author{
POR \\ ANTONIO FERNÁNDEZ-PUERTAS \\ Catedrático de la Universidad de Granada
}

The Córdoba Mosque was designed with the proportional Pythagorean system that is based on the side of a square $(=1)$, its diagonal $(=\sqrt{ } 2)$, and the successive proportional rectangles that are formed with the diagonal of the previous rectangle. The 8th century mosque had a square ground plan, its 9th century prolongation formed a $\sqrt{2}$ rectangle; the enlargement of the patio gave a $\sqrt{3}$ rectangle; the extension of al-Hakam II used a $\sqrt{3}$ rectangle plan at a reduced scale; and that of Almanzor used two large $\sqrt{3}$ rectangles.

En 1979 publiqué el trazado proporcional de las ventanas de la Bāb al-Uzarā', Puerta de los Ministros - hoy llamada de San Esteban-, al estudiar su decorado según los dibujos hechos por el arquitecto don Félix Hernández Giménez, y de los que me había facilitado una copia para estudio y publicación si lo deseaba a principio de los 1970 2.

Cuando dispuse posteriormente de un alzado completo de esta fachada, hecho por fotogrametría, comprobé primero si las medidas de la parte baja y de las altas inmediatas al alero y almenas eran fiables; tras haberme asegurado comencé a estudiar el trazado proporcional de la fachada entera, y encontré dos sistemas de diseño, uno de los cuales he publicado en 1999, tras una espera de casi dos décadas en la carpeta correspondiente por causas ajenas a mi voluntad ${ }^{3}$; el otro método de trazado espero que vea también pronto la luz. Inicio aquí, en esta Revista, el primero de varios trabajos sobre el sistema proporcional con el que la mezquita de Córdoba entera fue concebida y trazada, y que es el pitagórico heredado de la Antigüedad Clásica grecorromana que llegó al emirato omeya de Córdoba de los siglos viII y IX, y luego pasó al arte del califato, y pervivió bajo los taifas, almorávides, almohades y nazaríes ${ }^{4}$.

\footnotetext{
${ }^{1}$ En el XXV aniversario del fallecimiento del Arquitecto Dr. D. Félix Hernández Giménez.

${ }^{2}$ Antonio Fernández-Puertas, «La decoración de las ventanas de la Bāb al-Uzarā' según dos dibujos de don Félix Hernández Giménez, en Cuadernos de la Alhambra, 15-17, Granada 1979-1981, pp. 165-210, figs 1-56, láms. I-XXVIII, especialmente pp. 167, 170-176, figs. 2-12.

${ }_{3}$ Antonio Fernández-Puertas, «Uno de los dos trazados proporcionales de la Bāb al-Uzarā’», en Miscelánea de Estudios Árabes y Hebraicos, 48, Granada 1999, pp. 59-104, fig. 1-34, láms. I-II.

${ }^{4}$ Antonio Fernández-Puertas, The Alhambra. I. From the Ninth Century to Yüsuf I (1354). Plates by Owen Jones. Foreword by Godfrey Goodwin. Saqi Books, 1997, pp. 16-78; figs. 4-62; especial. 16-19. fig. 4 y bibliografía dada sobre el tema del sistema proporcional en la nota 10.
} 

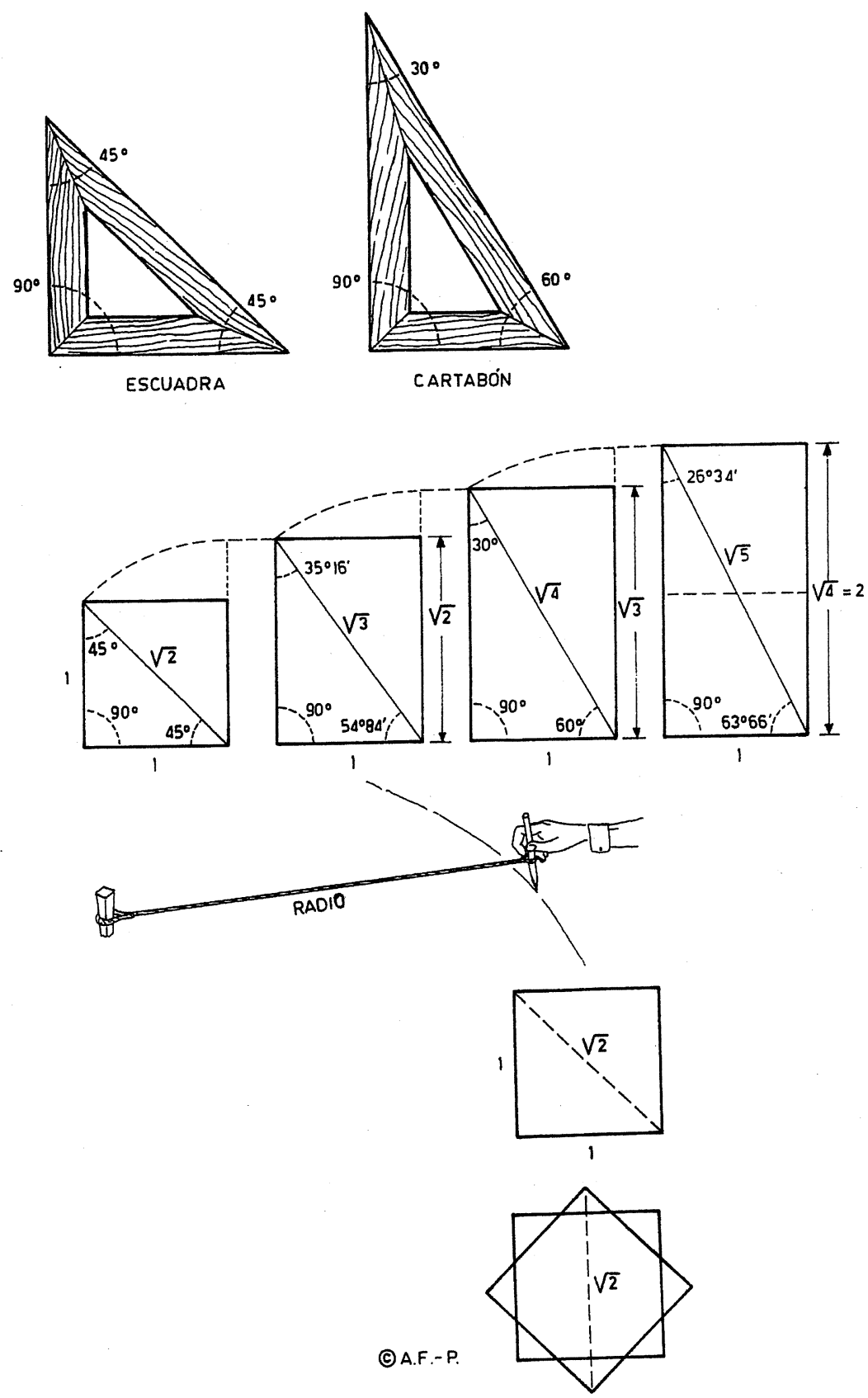

Fig. 1.

\section{El sistema proporcional: explicación general}

Esta explicación verbal se entenderá mejor si se siguen los pasos dibujados en la figura 1 . Si se da al lado de un cuadrado - cualquiera que sea su medida - el convencional valor de la unidad (=1), la diagonal de ese cuadrado es $\sqrt{2}(=1.4142 \ldots)$, o sea, un valor inconmensurable, como enseña el teorema de Pitágoras. Por lo tanto, si tomamos el lado de este cuadrado (=1) como el lado menor de un rectángulo, y a su lado más largo le damos la longitud de la diagonal del cuadrado, habremos obtenido un rectángulo proporcional $\sqrt{2}$ (fig. 1). A su vez, éste rec- 
tángulo $\sqrt{2}$ tiene una diagonal con valor de $\sqrt{3}$, como confirma una vez más el teorema de Pitágoras. De este modo, tras repetir la operación, obtenemos un rectángulo $\sqrt{3}$ (fig. 1). Si volvemos a realizar otra vez la operación hallamos un rectángulo $\sqrt{ } 4$ (es decir, un doble cuadrado), y así sucesivamente. Por el mismo principio, si se gira cualquier cuadrado cuyo lado es la unidad (=1) para formar una estrella de ocho puntas, la altura total de esta estrella será la $\sqrt{ } 2$, como se puede ver en la figura 1 . El lector que siga estos primeros pasos sencillos podrá comprender lo que voy a desarrollar en este trabajo y los siguientes ${ }^{5}$.

Sobre el trazado proporcional de la planta algo he publicado ya acerca de la primera ampliación de la mezquita en el siglo Ix por el emir 'Abd al-Rahmān II y la realizada por el califa al-Hakam II en los $960^{6}$. Todo el trazado de plantas y alzados de la mezquita se hizo por los sucesivos arquitectos con el sistema proporcional inconmensurable pitagórico expuesto.

\section{Las plantas utilizadas}

Para descifrar el trazado proporcional de la mezquita con sus sucesivas ampliaciones me atuve, por su total fiabilidad y acotamientos, a las plantas que don Félix Hernández Giménez publicó en su monografía sobre El codo en la historiografía árabe de la mezquita mayor de Córdoba ${ }^{7}$, de las cuales hice en 1978-1979 unos calcos exactos en vegetal a mayor tamaño para poder trabajar sobre el tema de la proporción. Una vez hallados los sucesivos pasos escribí el texto en 1980-1981 que ahora he retocado en su comienzo y algo en su conjunto.

A dichas plantas esquemáticas acotadas he añadido en mis calcos algunos elementos arquitectónicos de los que trato en el trabajo: 1) Las figuras 2 y 3 presentan los contrafuertes exteriores de la qibla de la mezquita de 'Abd al-Raḥmān I. 2) Las figuras 7, 8, 10-12, 14-16, muestran la planta del alminar de 'Abd al-Rahmān III con el muro divisorio N.-S. y las escaleras en torno a sus machones rectangulares. 3) Las figuras 10-16 presentan abierto el hueco de la caja del minbar, cegado desde 1815-1818. Para ello se ha tenido que desplazar algo la puer-

\footnotetext{
${ }^{5}$ Para un estudio de este sistema proporcional, véase Thomas TAYlor, The Theoretic Arithmetic of the Pythagoreans, with an «Introductory Essay» by Manly Hall, New York, 1973, ch. XIII: «On the Method of Discovering the Commensurability, or Incommensurability of these Numbers». JAY HAMBIDGE, The Elements of Dynamic Symmetry, New York, 1967, pp. 1724, 33-58. P. H. Scholfield, The Theory of Proportion in Architecture, Cambridge, 1958, pp. 12-13, nota 1. Frank Land, The Language of Mathematics, London, 1960, pp. 132-202. Matila GHYKa, The Geometry of Art and Life, New York, 1977, pp. 7-19; A Practical Handbook of Geometrical Composition and Design, London, 1956, pp. 3-15, figs. 1-17; Hambidge's Technique for Realizing Dynamic Symmetry, pp. 16-22, figs. 20-26; Estética de las proporciones en la naturaleza y en las artes, Barcelona, 1983; El número de oro. I. Los ritmos, Barcelona (sin fecha), pp. 25-144. RoBERT LAWLOR, Sacred Geometry, Philosophy and Practice, London, 1982, pp. 25-35. M. Borissa Vlievitch, The Golden Number and the Scientific Aesthetics of Architecture, with preface by LouIs HAUTECOEUR, London, 1958, pp. 12-29, especial. pp. 22-23, fig. 18. LouIS MEUNIÉ, L'architecture et la géométrie. Symétries et rythmes harmoniques, prefacio de AlBERT LUPRADE, Editions Vincent, Fréal \& Cie, Paris, 1968, es un libro útil para las proporciones de los edificios góticos. ERwIN PANOFSKY, Meaning in the Visual Arts , cap. 2: «The History of the Theory of Human Proportions as a Reflection of the History of Styles», Penguin, London, 1987, pp. 82-138.

${ }^{6}$ Antonio FernÁndez-Puertas, «Spain and North Africa», capítulo 6 del libro The Mosque. History, Architectural Development and Regional Diversity. Edited by Martin Frishman and Hasan-Uddin Khan. Thames and Hudson, 1994, pp. 101117. En p. 102 escribo que: «La planta general, que había sido cuadrada, se convirtió en un rectángulo $\sqrt{2}$, dejando el área del patio sin cambiar pero alargando la sala de oración, que ahora pasó a tener cinco tramos», y se da un dibujo de línea en la p. 104. Al tratar del agrandamiento de la mezquita por el califa al-Hakam II en p. 104 especifico que: «El arquitecto, por lo tanto, cambió la dirección y redujo, en escala, el sistema proporcional. Esta siguiente prolongación de la sala de oraciones se construyó como un rectángulo $\sqrt{3}$, pero basado sobre la longitud del muro de qibla del siglo Ix, que hasta entonces había tenido el valor de la unidad (el lado del cuadrado original). Al darle el valor de $\sqrt{3}$, el arquitecto redujo el valor de la unidad a una escala menor». En la p. 109 añado al hablar sobre las bóvedas-lucernarios que «las tres en frente del miḥrāb son cuadrangulares, y están construidas según el sistema proporcional de $\sqrt{2}$.»

${ }^{7}$ Contribución al estudio del monumento, Madrid. Imprenta y Editorial Maestre, 1961, figs. 1-5, colocadas al final de la monografía.
} 


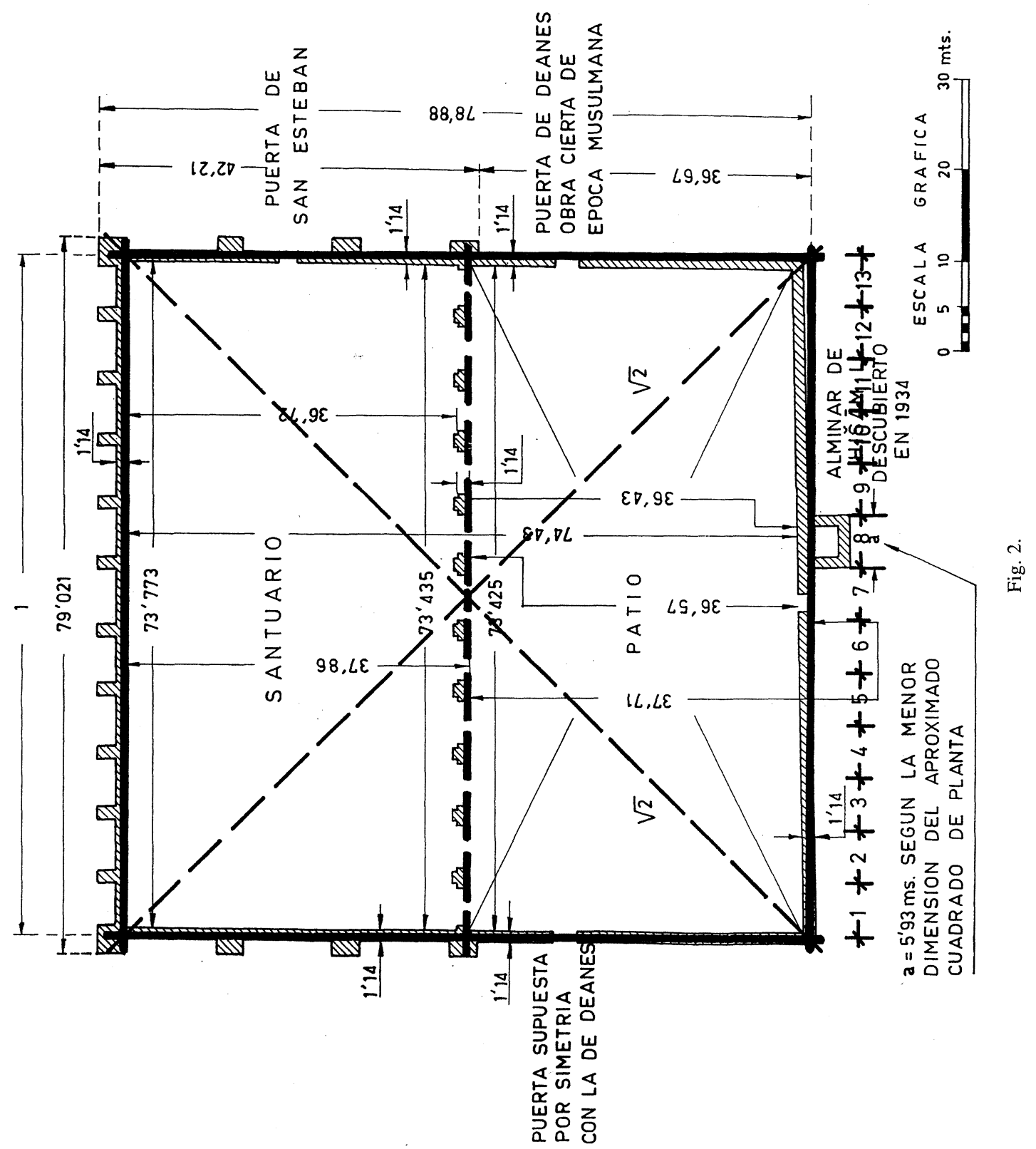




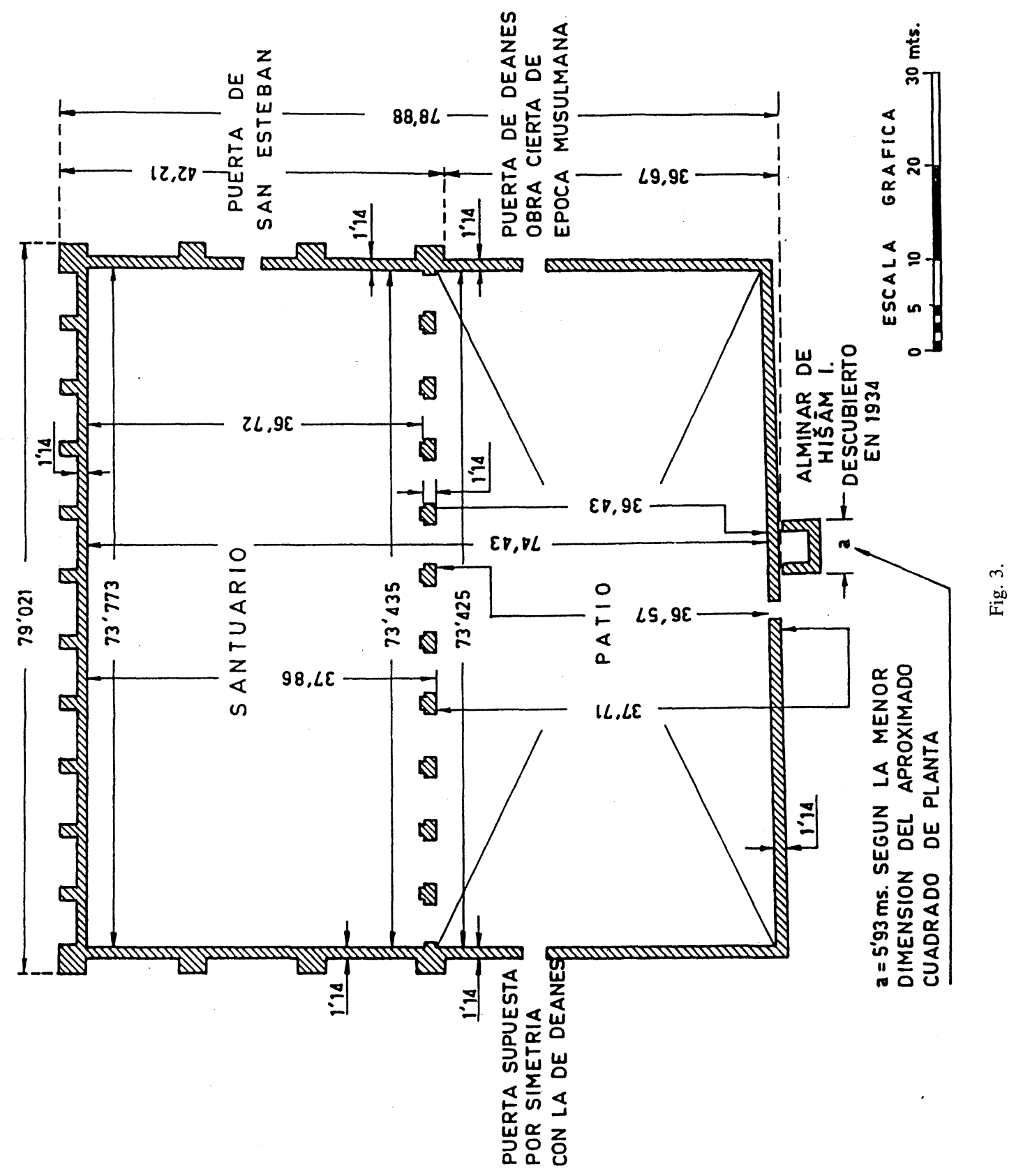


ta del sābāt hacia el O. Señalaré que las primeras estancias de la bayt al-māl y del sābāt están dibujadas cuadradas en vez de rectangulares como son; ésto se debe a que se ha dado el mismo grosor a los dos muros de las qiblas exterior e interior y a los más delgados de las compartimentaciones rectangulares que, en sentido N.-S. dividen en tramos la bayt al-māl y el sāba ăt. La figura 13, hecha sobre la hoja 2 del gran plano, que don Félix Hernández Giménez donó a la catedral, muestra lo que he expuesto. Como dato anecdótico diré que el insigne maestro dibujó el hueco de la caja del minbar a la derecha de la puerta y no a la izquierda como se encuentra (fig. 13) ${ }^{8}$.

\section{La unidad de medida dada por los historiadores musulmanes: el codo}

$\mathrm{Al}$ referirse al monumento los historiadores árabes dieron sus medidas en el sistema conmensurable musulmán de codos, derivado del romano a base de los pedes. Hay dos tipos de codos, el $m \bar{a}{ }^{\prime} m \bar{u} n \bar{l}$ que oscila de $47 \mathrm{cms}$ a $50 \mathrm{cms}\left(=2\right.$ pedes de $23^{\prime} 5 \mathrm{cms}$ a $\left.25 \mathrm{cms}\right)$ y el rašša $\breve{s} \bar{l}$ que varía de $60 \mathrm{cms}$ a $62^{\prime} 5 \mathrm{cms}$ (=2 pedes y medio). Los historiadores árabes, al dar las medidas de la mezquita de Córdoba ya construida (y no la proyectada por los arquitectos de los siglos VIII, IX y x en sus sucesivas ampliaciones), recurrían al sistema de medida fijo de codos por lo que las medidas fluctúan bastante, y aun más si utilizan uno u otro tipo de codo.

El mismo don Félix, al comenzar su mencionado estudio, dice [p. 7] que: «Las más de las noticias consignadas por los autores árabes respecto a dimensiones de la Mezquita de Córdoba resultan de imposible o, cuando menos, de muy aventurado aprovechamiento», y añade que debido al no aparecer las medidas del monumento con una misma unidad de medida nos «impide la confrontación de las equivalencias, tan dispares entre sí, que algunas de dichas noticias proporcionan para el patrón métrico utilizado... Por lo que respecta al codo ... la unidad [de medida] más empleada, ... [hay dos tipos] que discrepan bastante entre sí. Pero son también inclusibles entre dichos motivos: el descuido que haya podido presidir en la toma de los datos de que las citadas [p. 8] medidas proceden; el desprecio de las fracciones de unidad, frecuente en las escrituras árabes ... y finalmente, los hábitos locales en cuestión de mensura. Todo lo cual implica una cierta oscilación ... para cada tipo de codo en que las referidas medidas nos han sido suministradas.» A esto hay que añadir «los errores en que, la transcripción de manuscritos, pueda haberse incurrido», y las equivocaciones al realizar las sumas.

Según F. Hernández Giménez [p. 9], el valor del codo $m \bar{a} ' m \bar{u} n \bar{l}$ corresponde a $47 \mathrm{cms}{ }^{9}$ y el del codo rašs $\breve{a} \breve{s} \bar{l}$ a $58^{\prime} 76 \mathrm{cms}$, lo que supone una relación de 4:5, ya que el primero sería equivalente a dos pedes romanos de 23 ' $5 \mathrm{cms}$ y el segundo a dos pedes y medio. Este valor se basa en la obra del geópono hispanomusulmán de época nazarí Ibn Luyūn, quien en su tratado dice: «El codo ra $\breve{s} \bar{s} \bar{s} \breve{\imath}$ equivale a un codo y cuarto en relación con la medida del codo del bra-

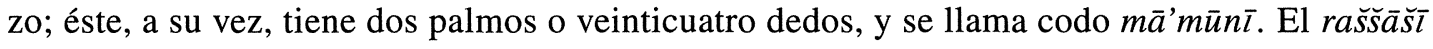
tiene treinta dedos y su uso fue establecido por el qassām de Córdoba Muḥammad b. Faraŷ al-

\footnotetext{
${ }^{8}$ La Mezquita de Córdoba: planos y dibujos, planos recopilados por Manuel Nieto Cumplido y Carlos Luca de Tena y Alvear. Colegio Oficial de Arquitectura de Andalucía Occidental, Córdoba, 1992, pp. 69, 70. La hoja 1 del plano muestra la mezquita del viII, su ampliación del Ix y a E. la correspondiente de Almanzor, así como la catedral cristiana, y se ha publicado en la página 70. La hoja 2 del plano presenta la ampliación de al-Hakam II, la de Almanzor a E. y las modificaciones de época mudéjar-cristiana, y se halla en la página 69.

${ }^{9}$ Leopoldo Torres Balbás, Arte hispanomusulmán hasta la caida del califato de Córdoba, t. V de la Historia de España, dirigida por Ramón Menéndez Pidal, Madrid 1965, p. 467, nota 8, donde acepta el valor del codo como $47 \mathrm{cms}$ al tratar del ancho del alminar del califa 'Abd al-Raḥmān III, de 8'46 ms, conocido tras la recuperación hecha por F. Hernández Giménez.
} 
Raššāš que grabó el patrón en una columna de la aljama cordobesa.» ${ }^{10} \mathrm{Al}$ Idrīsī también lo atribuye a «Muhammad ibn al-Faraŷ al-Raššāšs que había sido grabado sobre una de las columnas de la mezquita aljama de Córdoba ... la cual se toma hoy dia con preferencia como unidad base [de medida]». ${ }^{11}$ Sin embargo, este valor de $47 \mathrm{cms}$ para el codo $m \bar{a} ' m \bar{u} n \bar{\imath}$ cambia al dar las medidas de ancho, largo y alto del mịhrāb de al-Ḥakam II Ibn Baškuwāl en su Kitāb al-Sila ${ }^{12}$, y se aproxima de $49^{\prime} 1 \mathrm{cms}$ a $50^{\prime} 4 \mathrm{cms}^{13}$. Lo mismo ocurre cuando se trata del codo rašs $\bar{a} \breve{s} \bar{l}$, que oscila de los $58^{\prime} 76 \mathrm{cms}$ a los $60 \mathrm{cms}$ e incluso $62 \mathrm{cms}^{14}$.

Vamos a demostrar que tienen una explicación lógica estas incógnitas que dejaron el profundo estudio de F. Hernández Giménez sobre el valor de ambos tipos de codo en relación con la mezquita, porque los arquitectos usaron el simple trazado proporcional inconmensurable explicado, no sólo en la mezquita original del siglo viII, sino en las sucesivas ampliaciones de los siglos IX y x en plantas y alzados. Si este sistema se intenta ajustar al de medida mensurable de los codos, emergen las divergencias de valor en la unidad del codo de ambos tipos. Este es el único problema. Expuesto lo dicho, pasemos a analizar en este trabajo el trazado proporcional general de la planta de la mezquita de Córdoba, desde su creación por 'Abd al-Raḥmān I, 785, hasta la última ampliación hecha por el hậŷib Almanzor en el 988.

\section{La planta de la mezquita de 'Abd al-Raḥmān I (785)}

El arquitecto hizo tabula rasa de los edificios preexistentes en dicho lugar, superpuestos en diversos estratos por haberse sucedido desde época romana a la cristiano-visigoda según han mostrado las excavaciones de F. Hernández Giménez ${ }^{15}$. Tras ello, trazó el arquitecto del s. viII como planta del edificio un cuadrado, casi perfecto, pues en su esquina NO. se desvió algo (figs. 2 y 3). También hay un pequeño desvío en los muros perimetrales E. y O. que no son absolutamente paralelos ${ }^{16}$.

No obstante las pequeñas diferencias de medidas señaladas, la planta es un cuadrado: el lado S. de esquina a esquina del contrafuerte mide 79'021 ms; el lado E. 78' 88 ms desde la misma esquina a la linea del muro N.; el lado O., si se corrige la desviación de su ángulo NO.,

10 Joaquina Eguaras IbáNéEZ, Ibn Luyūn: Tratado de agricultura, Patronato de la Alhambra, Granada 1975, pp. 183-184 y especial. 187. LeRChundi y Simonet, Crestomatía arábigo-española. Vocabulario, p. 124. F. HernÁndez Giménez, El codo, p. 9 , nota 1 .

"F. Hernández Giménez, El codo, p. 10, nota 1. A. Dessus Lamare, Description de la Grande Mosquée de Cordoue, texto árabe y trad. francesa acompañada de notas, del relato de Idrīsī, p. 50, n. ${ }^{\circ} 149$.

12 Edición Francisco Codera, Bibliotheca Arabico Hispana, t. I-II, Madrid 1883. Hay otra edición de Insān 'Abbās, Beirut, 1965.

13 F. HeRnÁndez Giménez, El codo, pp. 12-13.

14 A. FernándeZ-Puertas, The Alhambra, I, p. 18, notas 11-13.

15 Como el pavimento de mosaico geométrico romano hallado bajo el santuario, cfr. J. M. BLÁzquez, Mosaicos romanos de Córdoba, Jaen y Málaga, en Corpus de mosasicos de España, fascículo III, Instituto Español de Arqueología «Rodrigo Caro» del Consejo Superior de Investigaciones Científicas, 1981, pp. 34-35, lám. 20. Asimismo, aparecieron los restos de una iglesia cristiana relativamente pequeña bajo el suelo del oratorio de la mezquita. Restos de una construcción pobre de mampuesto, no del todo excavado, fragmentos de mármol y de piedra, dieciséis piezas de cerámica extraídas de un pozo en abril de 1934 a la entrada de la Puerta de los Ministros - hoy todas ellas en el Museo Arqueológico Provincial —, un fragmento de un sarcófago icónico de mármol blanco, etc. Cfr. Manuel Nieto Cumplido, La Catedral de Córdoba, Publicaciones de la obra social y cultural de Cajasur, Córdoba, 1998, pp. 40-46.

${ }^{16}$ F. HeRń́NDEZ GiméneZ, El codo, p. 17, nota 2: «Los costados E. y O. de la primitiva Mezquita, no son paralelos uno al otro, sino que convergen simétricamente hacia N., en relación con el eje de la nave central, que, por su parte, es perpendicular a los testeros N. y S. de la zona del oratorio. De ello resulta que el ancho interior del santuario de 'Abd al-Rạ̣mān I, a lo largo de su muro de fondo, excede en $33^{\prime} 8 \mathrm{cms}$ de ese mismo ancho, tomado junto al testero de fachada al patio y cosa análoga ocurre en lo ampliado por 'Abd al-Raḥmān II, con diferencia de $57 \mathrm{cms}$ entre las medidas interiores a lo largo de los testeros N. y S. del oratorio de la mezquita, luego de realizada dicha ampliación.» 
también mide 78'88 ms. Es decir, la diferencia de 14 cms y 1 milímetro, es nada dado las longitudes expuestas ${ }^{17}$.

El arquitecto dividió este cuadrado de planta por la mitad en sentido E.-O., y dispuso en la parte meridional el santuario de once naves, y en la parte septentrional el patio rectangular sin galerías adosadas a su muro perimetral, con tres probables puertas de acceso al mismo: la N. axial a la nave central del santuario; la supuesta puerta lateral E., simétrica a la llamada de los Deanes, para facilitar el acceso a la mezquita a los fieles desde la parte oriental de Córdoba; y la lateral O. conocida hoy como Puerta de los Deanes, rehecha en época musulmana y después en época cristiana en la segunda mitad del siglo XIV, y en 1999-2000 en que se han repuesto sus dovelas y se ha suprimido la viga de madera del siglo XIV que sujetaba el descompuesto dovelaje del vano.

Tras dividir en dos rectángulos el cuadrado en sentido E.-O. y trazar el eje central N.-S. de la mezquita (fig. 4), se obtiene en cada rectángulo un doble cuadrado o rectángulo $\sqrt{ } 4$, cuya diagonal es $\sqrt{ } 5$ (fig. 4); luego todo el sistema de rectángulos proporcionales progresivos originados del cuadrado - es decir el sistema pitagórico de proporciones-, lo conocía el genial arquitecto del siglo viII, quien lo había aprendido de sus maestros, probablemente sirios e hispanos.

El muro perimetral del patio se contruyó sin contrafuertes, Sin embargo, dicho muro en el santuario, a E. y O., se dividió en ambos lados en tres tramos iguales entre sí, y, además, cuadrados al tener igual anchura que altura si se suprime el friso de almenas, como ya señalé al estudiar el trazado proporcional de la Bāb al-Uzarā' ${ }^{18}$. El arquitecto se valió de los contrafuertes intermedios decorativos, que actuaron a modo de «fuelle» para conseguir las medidas exactas requeridas. Los contrafuertes a E. y O. y en línea con la arquería de la fachada del santuario al patio, tienen una función arquitectónica; los contrafuertes que traban el muro de la qibla a los de E. y O. fueron ejecutados con cuidado en la unión de sus sillares, pues el punto débil de toda construcción son las esquinas, las cuales hay que reforzar contra cualquier movimiento causado por los empujes arquitectónicos, movimiento del terreno, o terremoto. El muro S., el de la qibla, no tuvo en el s. viII el miḥrāb saliente, sino un simple nicho empotrado en el mismo (fig. 4) ${ }^{19}$.

La Bāb al-Uzarā' - hoy llamada de San Esteban_, se situó en el tramo central de los tres que ofrece el muro O. del santuario (figs. 2-4). Era la única que comunicaba a éste directamente con la calle, estaba situada casi al frente del alcázar emiral — luego el califal—, quizá hacía juego con una fachada similar del mismo, por donde el emir salía con su corte de ministros y altos cargos y entraba por la Bāb al-Uzarā' al santuario ${ }^{20}$, sin tener que pasar por el patio o ir a la miḍa ', por venir ya con las abluciones hechas y tener más seguridad física al entrar próximo a la qibla y su mihrāb central.

17 F. HeRnÁndez Giménez, El codo, p. 15, donde dice sobre la planta cuadrada : «Y la presunción a que induce el análisis de esa medida de 80 codos acabada de citar, de que las partes cubierta y destechada de la Mezquita de 'Abd al-Raḥmān I fueron iguales entre sí en profundidad, se convierte en certeza de que en la referida dirección de los dos citados sectores midieron realmente lo mismo, considerado que, por su propia sencillez, es sumamente verosímil que al planear el edificio se previeran idénticas entre sí, en superficie, las dos zonas en que orgánicamente había que dejarse repartido el mismo. Y ello mayormente tenido en cuenta que $\operatorname{los} 36^{\prime} 72 \mathrm{~ms}$ que, en sentido norte-sur, medía lo techado de la primitiva Mezquita, constituyen mitad justa de lo que de E. a O. medía ese primitivo santuario en su línea de separación entre patio y oratorio, y que, por tanto, de haberse dado dicha presumible identidad, la planta de la originaria aljama cordobesa hubo de constituir un cuadrado perfecto.»

18 A. Fernández-Puertas, «Uno de los dos trazados», pp. 64, 101.

19 Esto fue intuido por M. Gómez-Moreno y luego estudiado por mí. M. Gómez-Moreno, El arte árabe español hasta los almohades. Arte mozárabe, en Ars Hispaniae, t. III, Editorial Plus Ultra, Madrid 1951, p. 42, fig. 39. A. FERNÁndezPUERTAS, «La decoración», pp. 197-200, figs. 41 y 42, lám. XXV.

${ }^{20}$ KLAus BRISCH, «Zum Bāb al-Wazarā' der Hauptmoschee von Córdoba», en Studies in Islamic Art and Architecture in Honour of Professor K. A. C. Creswell, Cairo, 1965, pp. 30-48, especial. pp. 38, 46, 47. A. Fernández-Puertas, La fachada del palacio de Comares. Situación, Función y Génesis. The Facade of the Palace of Comares. Location, Function and Origins, I, Granada, Patronato de la Alhambra, 1980, pp. 46-53, en especial p. 53 nota 35 y pp. 230-234, en inglés pp. 233 y 234 nota 35. 


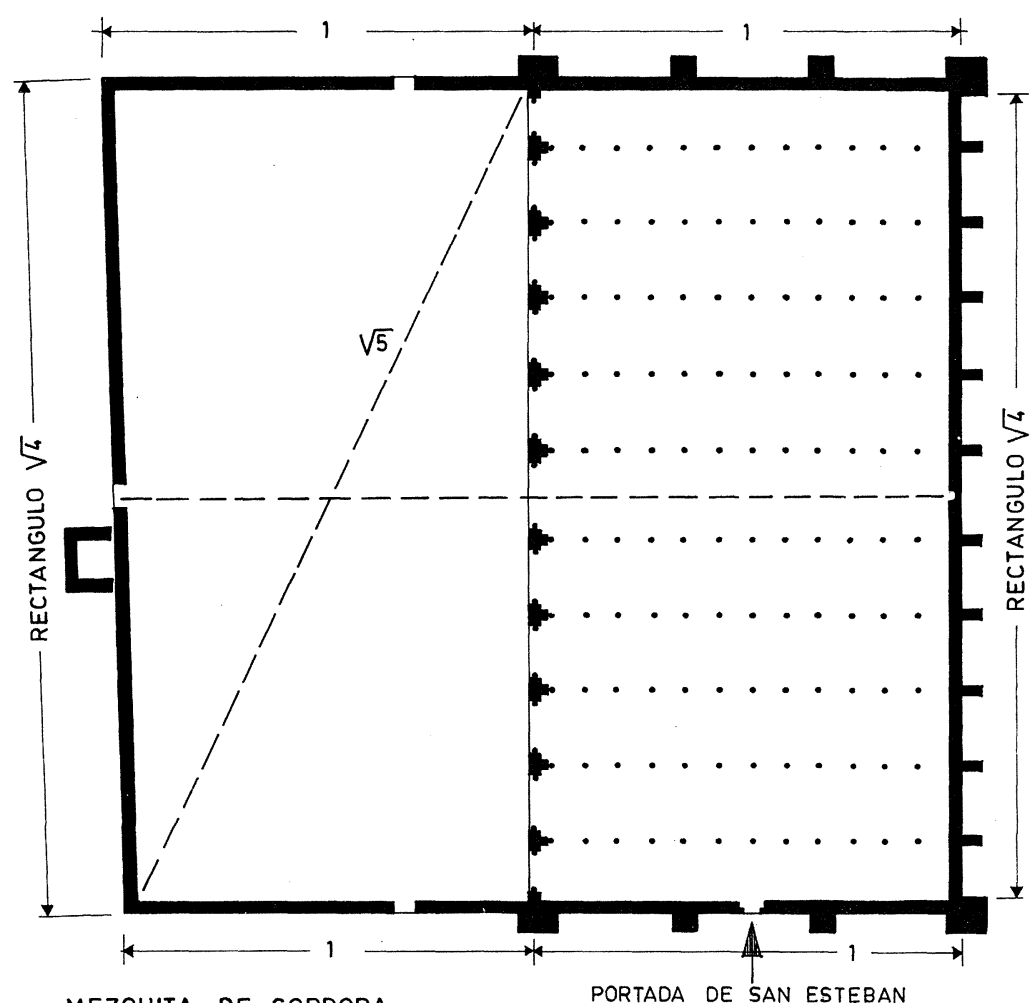

MEZQUITA DE CORDOBA SIGLO VIII

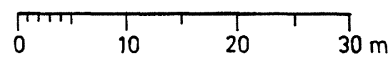

$\otimes$ 잉

$\otimes$

$\otimes$

$\otimes$

$\otimes$

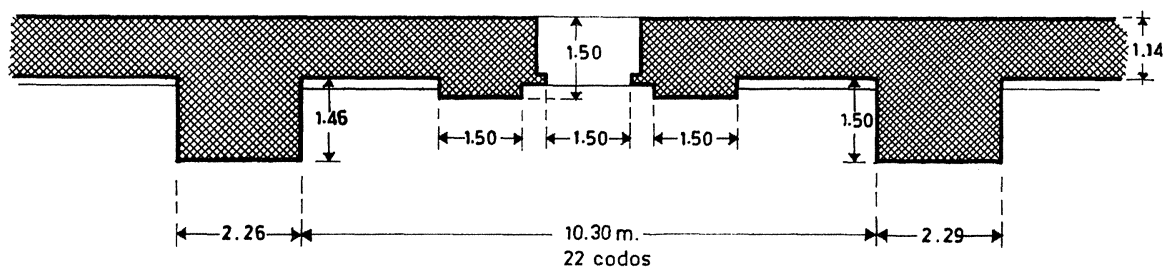

PORTADA DE SAN ESTEBAN PLANTA
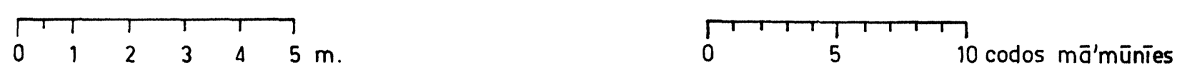

Fig. 4. 
En este estado quedó la mezquita de Córdoba cuando Hišām I sucedió a su padre en el emirato y procedió a completarla con una midqa 'adosada al muro perimetral E. de la nave once, según informa Ibn 'Iḍārī al-Marrākuš̄ī ${ }^{21}$. F. Hernández Giménez halló esta miḍ̂a' en excavación realizada en 1932, que dejó visitable ${ }^{22}$; en 1998 se ha limpiado y ampliado algo dicha excavación ${ }^{23}$. En 1934 F. Hernández Giménez, al explorar el area N. del patio para encontrar su primitivo muro de cierre, halló también la cimentación del alminar que elevó el emir Hišām I para completar la mezquita en el $796^{24}$, y lo dejó señalado en el empedrado del patio con sillares. Tenía 6’06 ms de lado, y estaba construido a la derecha de la puerta de entrada N. Su proporción de anchura con respecto al primitivo muro N. del patio era 1:13, estaba situado en lo que sería la división 8 de las 13 (figs. 2 y 3).

\section{La ampliación de 'Abd al-Rahmān II}

En los primeros años de los 840 'Abd al-Rạ̣mān II llevó a cabo la primera ampliación de la mezquita de Córdoba, que realizó hacia S. al derribar el muro de la qibla del 785 entre los contrafuertes que sobresalían exteriormente, y en parte perviven in situ al no haberles afectado la construcción de la catedral cristiana (figs. 5, 6).

¿Cómo ideó el arquitecto del siglo Ix esta ampliación? Aplicó el sistema proporcional explicado: agrandó el cuadrado original a un rectángulo $\sqrt{2}$ (fig. 5), es decir, tomó como lado unidad (=1) el lado del cuadrado de la mezquita del siglo viII (785), y abatió la diagonal del mismo (= $\sqrt{ } 2$ ) en sentido longitudinal sur, y así obtuvo el edificio ampliado con planta de rectángulo $\sqrt{ } 2$. Como se ve en la longitud de la diagonal, incluyó la cara externa de los contrafuertes angulares. Este trazado proporcional es otro de los puntos básicos, que corrobora los datos arquitectónicos y arqueológicos, de que la mezquita tuvo desde su construcción once naves y no nueve naves como dicen los textos árabes de Aḥmad al-Rāzī y de Ibn al-Nazzāām recogidos por Ibn Ḥayyān en su obra Kitāb al-Muqtabis II, en la parte que editó E. Lévi-Provencal al hallar el manuscrito. Me ocuparé de este problema en detalle en el trabajo en que analizo la planta de la mezquita del siglo vIII y su primera ampliación en el siglo IX ${ }^{25}$. Sin embargo, voy a indicar aquí algunas ca-

\footnotetext{
${ }^{21}$ Al-Bayān al-mugrib fì ijtișār mulūk al-Andalus wa-l-Magrib, trad. francesa por E. FAGNAN, Histoire de l'Afrique et de l'Espagne intitulée al-Bayano l-Magrib, 2 vols, Argel 1901-1904, t. II, p. 380

${ }^{22}$ F. HERnÁNDEZ GimÉNEZ, El codo, p. 16, nota 1, dice sobre la misma: «Que el resto del mid̄ă' aparecido en el subsuelo de la Mezquita, al E. inmediatamente del santuario de once naves ampliado hacia S. por 'Abd al-Rahmān II, midăa' que Ibn 'Idārī menciona como de Hišām I (1) y al que recubrió el arrecife organizado en contigüedad de aquella al ampliarla alHakam II, se acusa como francamente adicionado a ese santuario de once naves, y no como allí subsistente de edificación premusulmana». En la nota 1 añade que: «Hallamos los restos de este mida $\bar{a}$ y con ellos la citada calzada y una escalera de doble acceso a la Mezquita construida indudablemente en época de 'Abd al-Raḥmān II, en excavación realizada en 1932, en que todos ellos se dejaron visitables.»

${ }^{23}$ Pedro MarfiL Ruiz, «Avance de resultados del estudio arqueológico de la fachada Este del oratorio de 'Abd al-Rahmān I en la mezquita de Córdoba», en Cuadernos de Madinnat al-Zahrā', 4, Córdoba, 1999, pp. 175-207, figs. 1-11, láms. I-XII

${ }^{24}$ F. HeRnÁNDEZ Giménez, El codo, pp. 31, notas 1, 2, y p. 32, nota 1.

${ }^{25}$ El manuscrito del Muqtabis II dice que 'Abd al-Raḥmān II realizó una primera ampliación en el 833 agregándole las naves E. y O. - o sea, una y oncena - al oratorio del siglo viI, y una segunda ampliación en la década de los 840, al alargar la sala de oraciones hacia el S. Dos interpretaciones se han dado a esta crónica árabe. La primera es que se construyeron y adosaron al primer oratorio las naves de naciente y poniente, como parece evidenciar los modillones en cuarto de círculo propios de la ampliación hacia S. Han seguido esta interpretación dos autores. El primero, el descubridor del Muqtabis II, E. Lévi-ProvenÇAL, quien publicó en su lengua nativa, con el título francés «Documents et notules, I. Les citations du «Muqtabis» d'Ibn Hayyan relatives aux agrandisements de la Grande-Mosquée de Cordoue au IX ${ }^{\mathrm{e}}$ siècle», en Arabica, Leiden, 1954, pp. 89-92; recoge su opinión en su obra España musulmana hasta la caida del califato de Córdoba (7111031 de J. C.), en Historia de España, dirigida por Ramón Menéndez Pidal, t. IV, $3^{\text {a }}$ ed., Espasa Calpe, Madrid, 1967, pp. 168-169, nota 79 en p. 180. El segundo autor que siguió esta teoría fue ELIAS LAMBERT, quién, al darle a conocer E. LEV PROvENÇAL el hallazgo del manuscrito del Muqtabis II, y las noticias que contenía sobre la mezquita, realizó cuatro trabajos en relación con el tema: 1) «Las ampliaciones de la Mezquita de Córdoba en el siglo IX», en Al-Andalus, III, 1935, pp.
} 


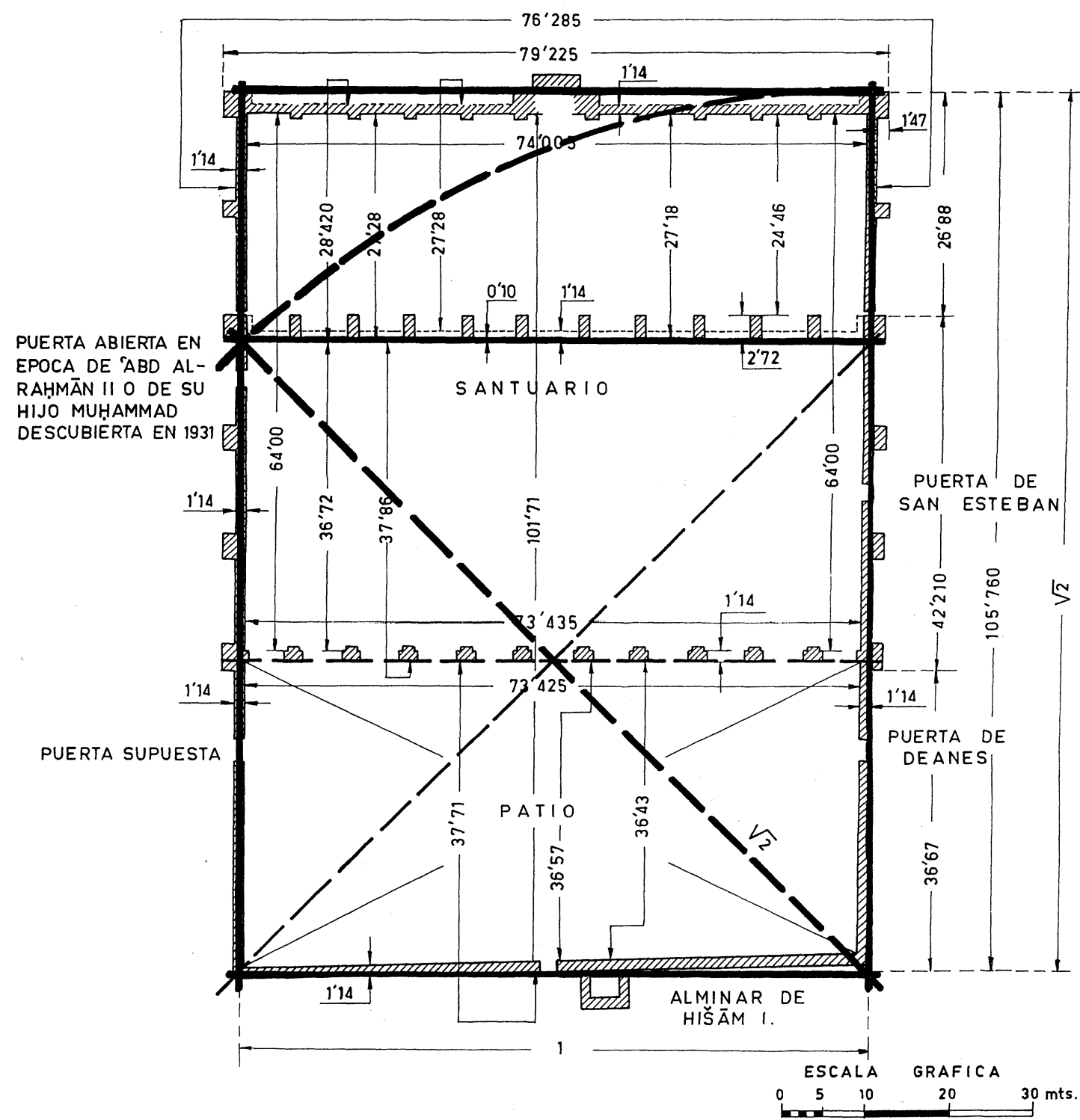

Fig. 5.

391-392; 2) «Las tres primeras etapas constructivas de la Mezquita de Córdoba», en Al-Andalus, III, 1935, pp. 139-143; 3) «De quelques incertitudes dans l'histoire de la construction de la Grande Mosquée de Cordoue», en Annales de l'Institut d'Etudes Orientales, Faculté des Lettres de l'Univeristé d'Alger, I, 1934-1935, Paris, pp. 176-188; 4) «Histoire de la Grande Mosquée de Cordoue aux VIII ${ }^{e}$ et IX ${ }^{e}$ siècles d'après des textes inédits» en Annales de l'Institut d'Etudes Orientales, Faculté des Lettres de l’Université d'Alger, II, 1936, Paris, pp. 165-179.

Sin embargo, la arquitectura, proporción y arqueología han demostrado que la mezquita del siglo viII tuvo once naves y era un cuadrado. Así han seguido esta opinión L. Torres BaLBás, quien tradujo al español el texto francés de Elias Lambert en «Nuevos datos documentales sobre la construcción de la Mezquita de Córdoba en el reinado de "Abd al-Rahmān II», en Al-Andalus, VI, 1941, pp. 412-422; Arte hispanomusulmán, pp. 386-393. F. HeRNÁndEZ GiméNEz, El codo, pp. 14-17. Yo sigo esta opinión que baso en las pruebas arqueológicas, arquitectónicas y en las nuevas que aporto sobre las proporciones del edificio en este trabajo y en «Uno de los dos trazados». Recientemente se ha publicado una magnífica edición facsímil de esta parte del Muqtabis II: Ben Haián de Córdoba (m. 469 H./1076 J. C.), Muqtabis II. Anales de los Emires de Córdoba Alhaquém I (180-206 H./796-822 J. C.) y Abderramán II (206-232/822-847). Edición facsímil de un manuscrito árabe de la Real Academia de la Historia (Legado Emilio García Gómez) al cuidado de Joaquín Vallvé Bermejo, Real Academia de la Historia, Madrid, 1999, p. XV, folios 139r. ${ }^{\circ}-142 r{ }^{\circ}$. La reforma primera a la que alude el Muqtabis II, en el 833, de añadir a $\mathrm{E}$. y $\mathrm{O}$. una nave hay que interpretarla como incorporar sendas naves una y oncena al oratorio de los hombres por destinar a las mujeres a las galerías del patio, que se construyeron bajo su emirato. 


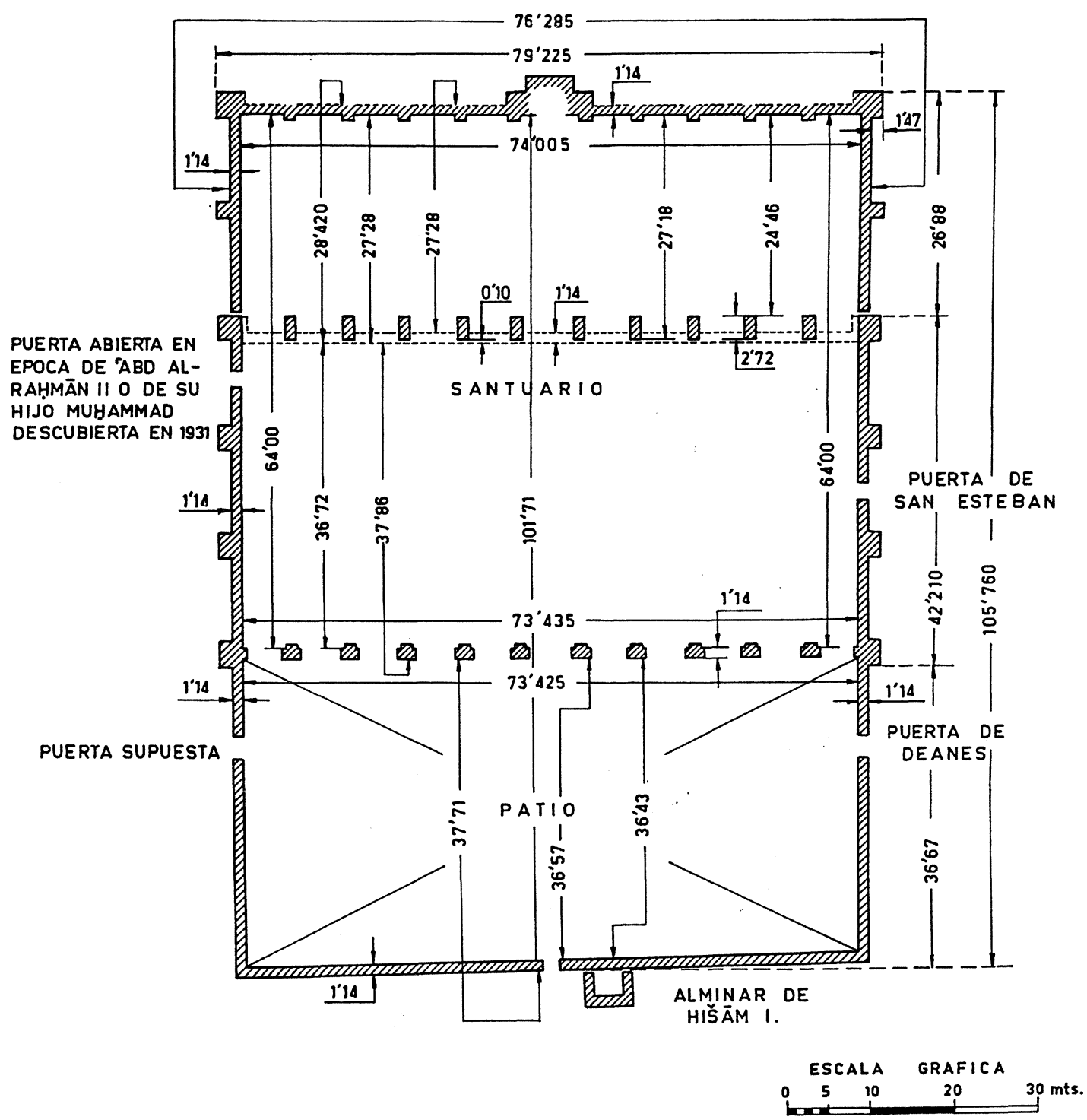

Fig. 6.

racterísticas del muro de la qibla del siglo ix en relación con el primitivo de la mezquita del siglo viII. Tras las excavaciones de F. Hernández Giménez se ha comprobado que el muro de la qibla del 785 de 'Abd al-Raḥmān I era una pared corrida sin obstáculos hacia el eje donde estuvo el mihrāb; los arcos extremos de las diez arquerías (el bajo de herradura de entibo y el alto de medio punto que soporta la canal y la techumbre), apoyan directamente sobre la cara interior de los contrafuertes, con los que los sillares de las dovelas se traban, por lo que no se necesita columna adosada. Había una diafanidad intencionada hacia el mihrāb. Además, los diez contrafuertes de las galerías sobresalían hacia el exterior como estrechas torres defensivas coronadas por almenas. Al ampliar la edificación del oratorio 'Abd al-Raḥmān II, los contrafuertes (arŷul) quedaron incluidos en la sala de oraciones, y los arcos de herradura de entibo y los altos de medio punto que iniciaban las arquerías arrancan de dichos contrafuertes sin apoyo de columnas. Es decir, se repitió a ambos extremos de los contrafuertes la misma solución, en un principio sólo hacia N. en el siglo viII, y en el siglo IX también hacia S. 
Sin embargo, la qibla de la ampliación de 'Abd al-Raḥmān II (siglo IX) muestra los contrafuertes de sus diez galerías salientes hacia el oratorio; los arcos extremos de herradura apoyan en columna adosada a los mismos, y los superiores de medio punto en pilar trabado a los contrafuertes. Esta solución del siglo Ix rompía la del muro liso del siglo viII, pero los contrafuertes salientes con las columnas adosadas es una disposición arquitectónica menos satisfactoria, pues impedía una visión clara y lineal del muro de la qibla y del mihrāăb ${ }^{26}$. En la excavación que realizó F. Hernández Giménez apareció que el mihrāab sobresalía, de modo escalonado, todo el ancho de la nave central y su cimentación de sillares avanza en el subsuelo de la llamada Capilla de Villaviciosa hasta aproximadamente el eje de columna del primer arco de la composición tripartita dispuesta de N. a S. subsistente en el lado E. de la qubba.

Esta enorme cimentación en su día estuvo vista, y muestra los sillares con sus extremos abiselados. Cuando el mihrāab se demolió en el 965 bajo al-Ḥakam II, no quedó rastro en el suelo de como pudo haber sido el nicho. No obstante, por la profundidad saliente de la cimentación, por la anchura de la misma y por la disposición de los dos pares de columnas que alḤakam II hizo trasladar a su mihrāa en el 965 , doy por seguro que el nicho fue una cámara con probable planta de arco de herradura, y con su arco de entrada también de herradura pero más bajo de impostas. Esto último se deduce de que, al reutilizarlas en el mihrāăb de al-Ḥakam II (965), se les ha añadido bajo el plinto un basamento rectangular cúbico para que alcancen la línea de impostas.

El miḥrāb de la ampliación de 'Abd al-Raḥmān II hubo de ser de construcción exquisita y lujosa, ya que, según cuenta Ibn 'Iḍārī al-Marrākuš̃i: «En ŷumādà II 354 [junio 965] concluyose la cúpula que domina el miḥrāb», es decir, el lucernario abovedado central que da acceso al nicho, en el cual se siguió trabajando hasta el otoño. Entonces,

«desde al-Madīna al-Zahrā' fue a caballo al-Hakam II en la segunda década de sawwāl 354/9=19 octubre 965, a visitar las obras y enterarse de su marcha. En tal ocasión ordenó desmontar $\left(i q l \bar{a}^{\top}\right)$ cuidadosamente las cuatro magníficas columnas (sawārì), sin par, que arrimadas a las jambas del viejo mihrāb (bi- 'iḍa dat al-mihrāa b al-qadīm ) [de la ampliación de 'Abd al-Rạ̣mān II], sostenían su arco de entrada, para colocarlas en el nuevo cuando la obra de fábrica estuviera ultimada ('inda itqāni iḥkāmi-hi wa-ikmāli-hi)» ${ }^{27}$.

El reutilizar los dos bellísimos pares de columnas para el nuevo mihrāb califal implica la belleza ornamental que éste tenía y cuya cámara fué demolida hasta cimentación para que des-

\footnotetext{
${ }^{26}$ F. Hernández Giménez, El codo, p. 18, nota 1. Al hablar de los 50 codos mā'mūnīes que Ibn 'Idārī consigna en longitud a la ampliación de 'Abd al-Raḥmān II, de 48'9 cms., dice en nota 1: «Al tomar esta medida [24.46 ms divididos por $50=48.9 \mathrm{cms}$ ] hemos partido del supuesto de que las arcadas contiguas al testero de mediodía de la ampliación de 'Abd al-Raḥmān II apoyaban en fustes y pilastras adosadas al muro de qibla, similarmente a como sucede en el testero N. de la primitiva Mezquita. Semejante disposición requiere que el muro de la qibla de la ampliación de referencia se hallase centrado con el construido por al-Hakam II, en la divisoria de lo adicionado por él y lo preexistente del edificio. Hace presumible que en realidad sucediese lo acabado de indicar, el que, contrariamente a lo que ocurre en la Mezquita originaria, las fundaciones de lo ampliado por 'Abd al-Raḥmān II son impecables, circunstancia que es natural que aconsejara el aprovechamiento de las que, de aquéllas, corresponden al muro del fondo de la primera ampliación, como cimentación del que vino a sustituirlo, lo que extraña la coincidencia de las respectivas líneas de eje de ambos. Consiguientemente, como el grueso del primero de tales muros parece haber sido de $1.14 \mathrm{~m}$., en tanto el grueso del segundo se eleva a $1.66 \mathrm{~ms}$., es casi seguro que, de haber existido en aquél pilastras adosadas, tuviesen éstas 0’37 m. de saliente y no $0.11 \mathrm{~ms}$. como término medio tienen las allí existentes.»

${ }^{27}$ Al-Bayān Al-Mugrib fĩ mulūk al-Andalus wa-l-Magrib, ed. R. Dozy, Leiden, 1848-1851, t. II, texto ár. 253-254, trad. francesa E. FAGNAN, Histoire de l'Afrique et de l'Espagne intitulée al-Bayano l-Mogrib, 2 vols., Argel, 1901-1904, II pp. 392-393. Texto recogido por E. LÉvi-Provencal, Inscriptions arabes d'Espagne, 2 vols., Paris 1931, p. 14. L. ToRres BaLBÁs, Arte hispanomusulmán, p. 478, nota 11. El vocablo iḍāda, pl. iḍādat significa, el pie derecho o jamba de un vano.
} 
apareciera su rastro sagrado; algo similar a lo que posiblemente ocurrió con el nicho empotrado del mihrāa de la primera mezquita, cuya ornamentación fragmentada quedó enterrada bajo el suelo sagrado del oratorio y F. Hernández Giménez descubrió en la excavación de este sector en 1931-1932 ${ }^{28}$.

Ya he apuntado en otro lugar ${ }^{29}$ que en líneas generales debió ser similar en planta y alzado al mihrāb de la mezquita de Qayrawān, construida por Ziyādāt Allāh en 836, y remodelada por Abū Ibrāhīm Aḥmad en 862-863. Debió además servir el miḥrāb de 'Abd al-Raḥmān II de modelo a los ábsides mozárabes del reino astur-leonés; la teoría de que el mihrāa de al-Ḥakam II provenga de éstos me parece un total desacierto por desconocer el arte musulmán de los siglos viII al x, como ya he expuesto, y volveré sobre el tema en el próximo trabajo sobre el estudio proporcional en detalle de las plantas de la mezquita del siglo viII y del ix.

Con la ampliación del oratorio hacia S., sus muros perimetrales E. y O. se subdividieron en dos tramos iguales mediante un contrafuerte ornamental intermedio rectangular, de menor anchura que el angular de la qibla de la mezquita del siglo viII y el nuevo contrafuerte en el ángulo de la qibla del siglo Ix (figs. 5 y 6). Así, pues, cada muro lateral del oratorio presentaba ahora cinco tramos, los tres de la mezquita original y los dos añadidos en el siglo IX al ampliarla. El muro O. tenía desde el 785 la Bāb al-Uzarā' (Puerta de los Ministros), que en el siglo IX quedó descentrada. En época de 'Abd al-Raḥmān II o de su hijo Muḥammad I se abrió hacia E. otra puerta, necesitada para el ingreso directo en el santuario de toda la población que vivía en el sector oriental de Córdoba, y que F. Hernández Giménez halló en la excavación en 1931-1932; estuvo ubicada en el tramo central de los cinco, el tercero, es decir el más meridional de la mezquita del siglo viII. No se practicó puerta en ninguno de los dos nuevos tramos añadidos a S. - lo que en obra hubiera resultado más sencillo y económico一, por el principio de darle a ese lado naciente del santuario un eje simétrico.

Esta fachada E. con puerta central muestra «una escalera de doble acceso a la Mezquita, construida indudablemente en época de 'Abd al-Raḥmān II, en excavación realizada en 1932" ${ }^{30}$, que quedó visitable; en el plano F. Hernández Giménez fechó la excavación en 1931 en su rotulación (figs. 5 y 6). También en el mismo ha dejado marcado por interrupción donde los muros E. y O. se unieron al prolongarse el santuario, por mostrar distinta alineación. En esta excavación se aprecia como los muros externos de la mezquita estaban estucados para fingir sillares blancos con supuestas ranuras de color almagra, que no obedecen al despiece de la sillería real. Esto mismo se encuentra en otros lugares protegidos de la mezquita; y en la ciudad palatina de al-Zahrā' en la base de las torres a poniente de la terraza de al-Maŷlis al-Šarqī, Salón Oriental; en las torres del castillo de Baños de la Encina, éste de época de al-Ḥakam II. Esta técnica de estuco de fingir sillares blancos separados por tendeles rojo almagra sobrevive hasta lo nazarí ${ }^{31}$.

Las arquerías del siglo Ix ya muestran cimentación corrida a diferencia de las del siglo viII, y los contrafuertes de las diez galerías $(a r \hat{y} u l)$, que sobresalían al exterior de las qibla de 'Abd al-Raḥmān I quedaron incorporados al santuario, pues desmontarlos hubiera sido arruinar la mezquita primitiva no sólo por los empujes sino por la falta de cimentación bajo las columnas.

Tras la ampliación del oratorio por 'Abd al-Raḥmān II hacia el S., la Bāb al-Uzarā' (Puerta de los Ministros), quedó desplazada como acceso inmediato del emir, sus visires y cortesa-

\footnotetext{
28 A. Fernández-Puertas, «La decoración», pp. 197-200, figs. 41 y 42, lám. XXV.

29 Antonio Fernández-Puertas, «Introducción» al libro de Purificación Marinetto Sánchez, Los capiteles del palacio de los Leones en la Alhambra, Monográfica Arte y Arqueología, 32, Universidad de Granada y Diputación Provincial de Granada, Granada 1996, pp. XIX-LIX, especial. XXXI-XXXV, notas 9 y 10.

${ }^{30}$ F. Hernández Giménez, El codo, p. 16, nota 1. En la rotulación de los planos el texto dice: «Puerta abierta en época de 'Abd al-Rạ̣mān o de su hijo Muhammad descubierta en 1931".

31 A. Fernández-Puertas, The Alhambra, I, p. 308, nota 54.
} 
nos a la qibla y el mihrāab, tras cruzar la calle intermedia. La seguridad del soberano consistía en no exponerse - o lo menos posible - al contacto de masas de gente, pues algún fanático o asesino podía atentar contra su vida. La situación era en especial delicada al acudir la comunidad musulmana y el emir con su corte a la oración del Viernes. Así, pues, para seguridad física del soberano y para entrar y salir del oratorio, se procuró un acceso sin atravesar su sala de oración, y a línea con la qibla hasta alcanzar el nicho del mihrāa.

Por esta razón, en la segunda mitad del siglo ix el emir 'Abd Allāh, abuelo de 'Abd alRaḥmān III, abrió el vano para un postigo en el muro O. del oratorio (figs. 7 y 8), en el quinto tramo, el más meridional de los dos añadidos en la ampliación de 'Abd al-Raḥmān II. El motivo de este vano fue realizar una entrada, lo más próxima posible al muro de la qibla y al miḥrāb de la ampliación de 'Abd al-Raḥmān II, desde el frontero alcázar emiral que estaba situado al otro lado de la calle, y de este modo evitar riesgos al soberano.

Este postigo practicado en el muro O. del oratorio daba paso a un corredor elevado soportado por arcos - un $s \bar{a} b \bar{a} t$ - que por encima de la calzada comunicaba el oratorio con el alcázar y viceversa ${ }^{32}$. Este primer pasadizo sobre la calle duró hasta que el califa al-Ḥakam II realizó su ampliación y construyó el segundo sābāt, que fue destruido por el obispo Mardones en los primeros años del siglo XVII. Lo describió en el siglo XII al-Idrīsī y a fines del siglo XVI el canónigo de la mezquita-catedral Ambrosio Morales ${ }^{33}$.

\section{La ampliación de 'Abd al-Raḥmān III (951-952 y 958)}

El califa 'Abd al-Raḥmān III amplió el patio de la primitiva mezquita hacia N. y le construyó un nuevo y monumental alminar, derribando después el del emir Hišām I. ¿Cómo llevó a cabo dicha ampliación del patio? Pues, tomó la diagonal del rectángulo $\sqrt{2}$ de la planta de la mezquita — que tiene el valor de $\sqrt{3}$ - , y la abatió longitudinalmente sobre los lados E. y O., y construyó la nueva ampliación con planta de rectángulo $\sqrt{ } 3$ (fig. 7).

En la mezquita del siglo viII al agregarle el segundo emir, Hišām I, el alminar al testero N. lo hizo adosándolo por el exterior al muro N. del patio. Cuando el califa construyó el nuevo alminar éste quedó por dentro del muro perimetral, delimitado a O. por la galería del patio y a E. por la puerta del patio axial con la nave central del oratorio, la llamada en época cristiana Puerta del Perdón (figs. 7, 8). Este alminar de planta exterior cuadrada muestra su interior dividido por un muro en dirección N.-S. en toda la altura del hueco del mismo, por lo que resultan dos espacios rectangulares iguales a un doble cuadrado cada uno, es decir, sendos rectángulos $\sqrt{ } 4=2$, el único rectángulo proporcional cuyos lados son mensurables. En el interior de cada uno de ellos se dispuso un machón central en torno al cual se desarrollaba una escalera, que desde su arranque hasta la terraza de la qubba de los almuédanos estaba por completo separada de su homóloga; a una escalera accedían los almuédanos desde una puerta por la calle y a la otra desde una puerta accesible desde el patio (figs. 7, 8).

\footnotetext{
${ }^{32}$ L Torres BalBás, Arte hispanomusulmán, p. 415, notas 109 y 110. G. MarçaIs, Manuel d'art musulman, l'architecture. Tunisie, Algérie, Maroc, Espagne, Sicile. I. Du IXe au XII siécle, Paris, 1926, p. 220. Lucien Golvin, Essai sur l'architecture religieuse musulmane, t. 4, L'art hispanmusulman, Editions Klincksieck, Paris 1979, pp. 63-64, nota 111, y fig. 14 donde presenta una restitución del $s a \bar{a} b \bar{a} t$ del emir 'Abd Allāh mediante un gran arco por debajo del cual quedaba la calle y por encima el pasadizo cubierto; esta restitución hipotética es imposible desde el punto de vista arquitectónico, ya que los empujes, elevación de la luz del arco, y el edificio de la mezquita mismo muestra en la sillería que hubo de ser un pasadizo horizontal sobre arcos, como luego en los 960 repetiría al-Hakam II al hacer su ampliación y derribar este corredor por haber dejado de tener el uso para el que se había construido.

${ }^{33}$ L. Torres Balbás, Arte hispanomusulmán, p. 484. L. Golvin, Essai, t. 4, p. 67, fig. 15 donde da una restitución hipotética sobre arcos, que debieron ser más altos por el declive de la calle hacia el arrecife y el río.
} 


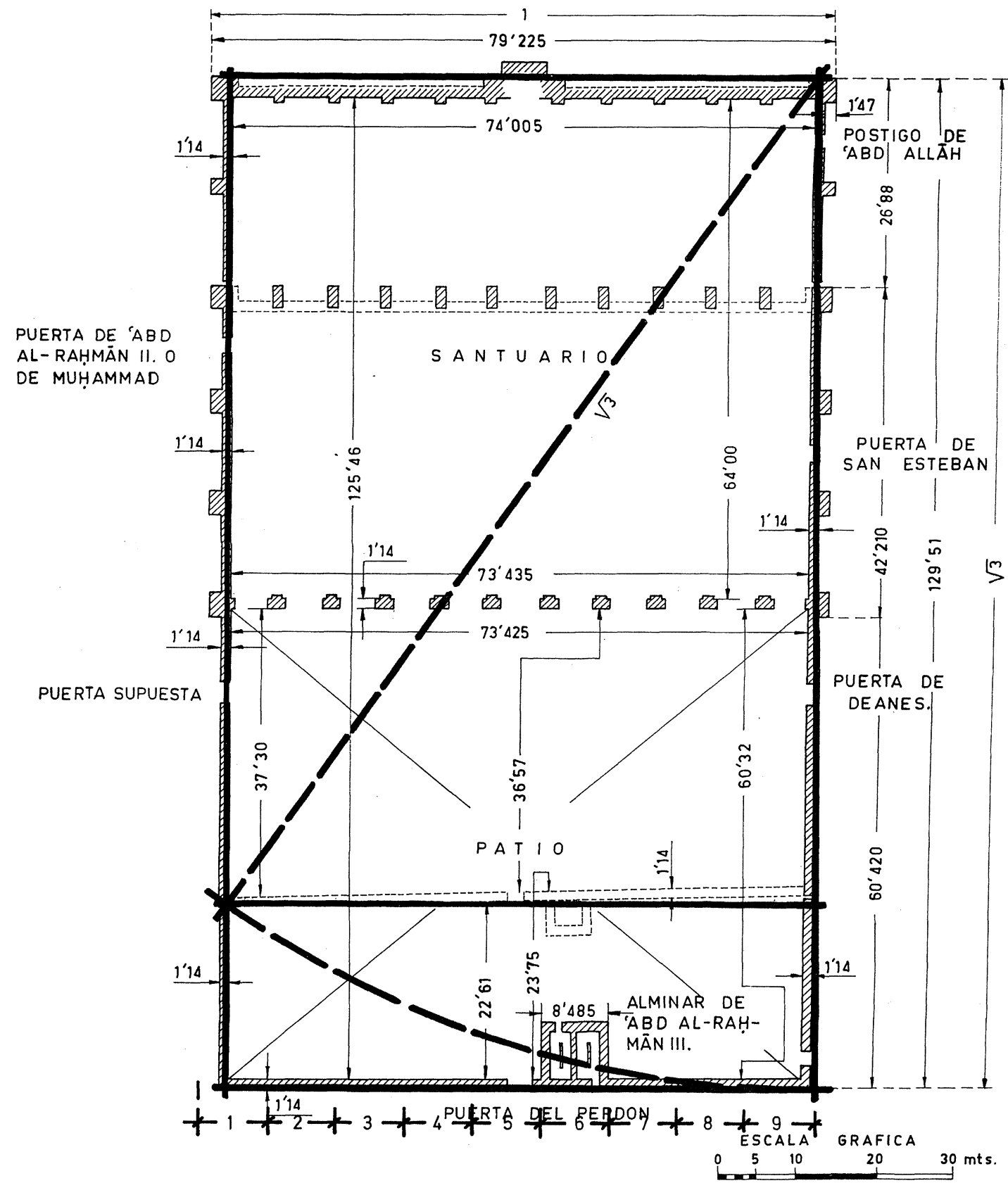

Fig. 7.

Si se toma el ancho de la planta del alminar en relación con la longitud total del muro N. que cierra el patio de la mezquita, se observa que se aproxima a una novena parte (fig. 7) ${ }^{34}$. Desde lo alto de la actual torre que envuelve al alminar se ve a O. hoy día la ciudad de alZahrā', que sería mucho más visible en el siglo x, cuando la madina palatina estaba por com-

${ }^{34}$ En la figura se han representado nueve partes, y en la 5 está la Puerta del Perdón a eje con la nave axial del oratorio, y en la sexta el alminar. Pero estas divisiones no son por completo exactas, pues para ver cuantas veces el ancho de la planta del alminar se repetía en la longitud del muro N., he tenido que prolongar el ancho de la planta del alminar en el lado de naciente hasta el saliente de los contrafuertes orientales, lo que no he hecho en el lado de poniente del muro N. del patio, por lo que la medida del ancho de la planta del alminar sólo se aproxima a la novena parte. 


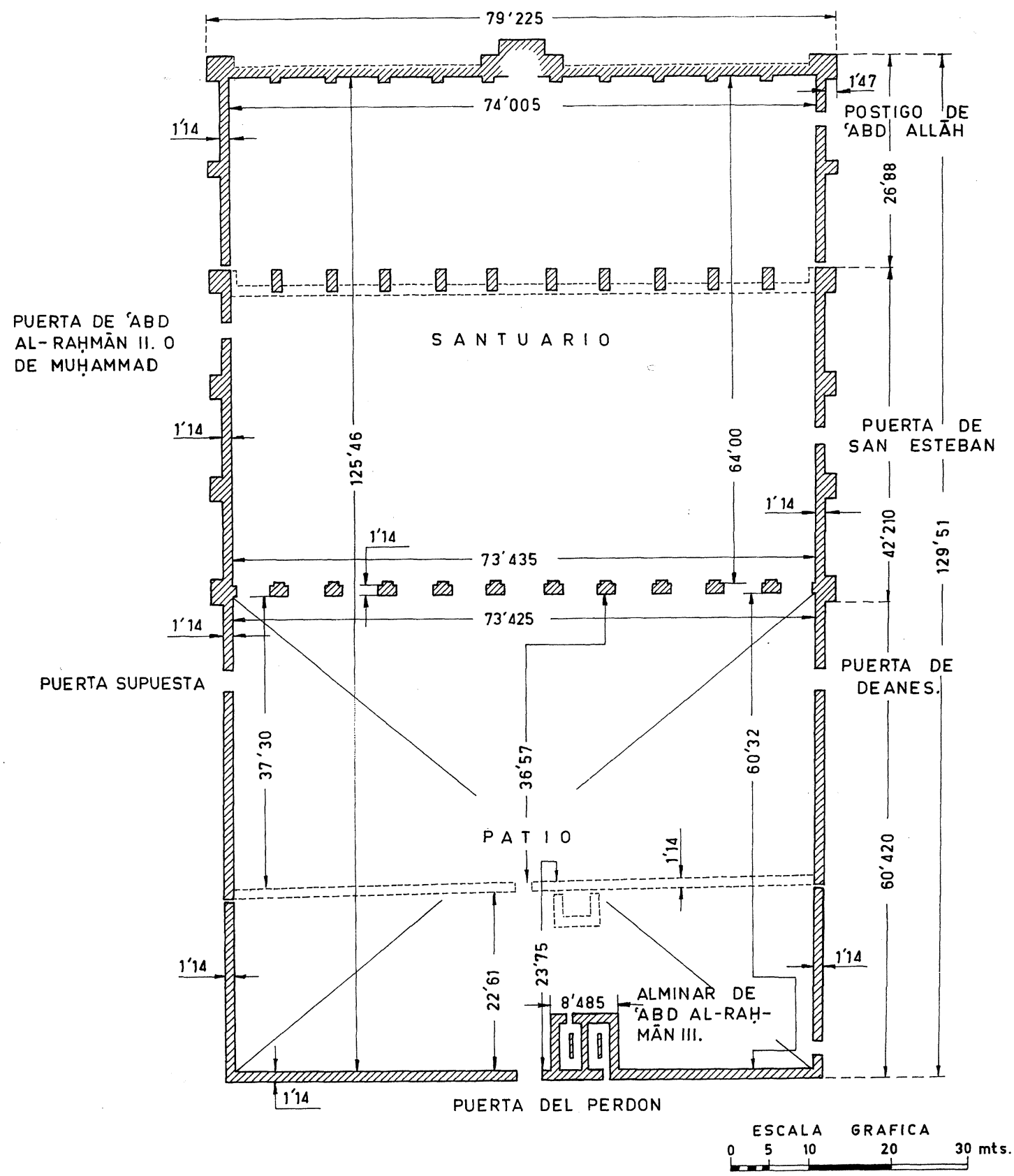

Fig. 8.

pleto en alzado y llena de vida. Supongo que desde este alminar, y desde el otro de la ciudad de al-Zahrā' se podrían hacer señales con espejos, banderas izadas, fuegos nocturnos, etc., aunque nada dicen los textos. Lo cierto es que siempre que he subido al cuerpo de campanas he observado que los almuédanos verían el movimiento viario de ida y vuelta a la ciudad palatina, así como las paradas hacia la misma, o las idas y venidas del califa y su familia a al-Zahrā', o hacia Córdoba. Supone F. Hernández Giménez que el hueco original del extremo septentrional del muro O. - hoy una puerta barroca- es de época de 'Abd al-Raḥmān III para ingresar de la calle a la galerías destinadas a las mujeres (figs. 7, 8). 


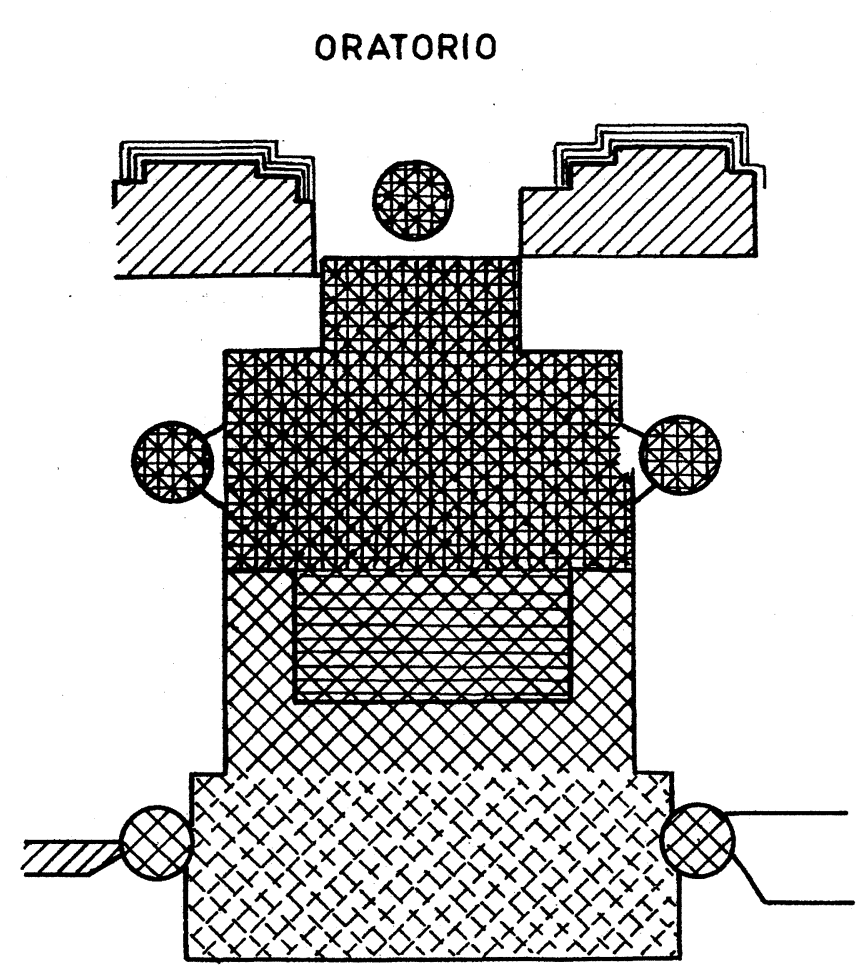

\section{ORATORIO}

PATIO
OBRA ORIGINARIA.

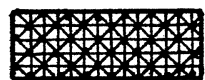

PILAR ADICIONAL ANTERIOR A 955

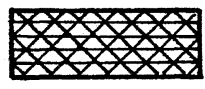

OBRA DE ABD AL RAHMĀN III

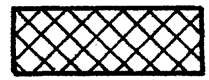

OBRA DE 'ABD AL RAHMÄN III RECONSTRUIDA CON ULTE RIORIDAD.

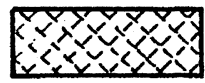

OBRA DEL SIGLO XVII

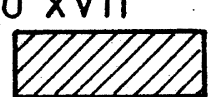

Fig. 9.

La fachada del oratorio del siglo viII hacia el patio sufrió a mediados del siglo x un paulatino desplome que amenazó inminente ruina, por lo que 'Abd al-Raḥmān III emprendió de inmediato su refuerzo, como estudió y publicó F. Hernández Giménez tras efectuar en la fachada las prospecciones pertinentes (fig. 9) ${ }^{35}$. Según la lápida en grafía cúfica colocada en la jamba derecha, u O., del arco de herradura de la puerta de acceso a la nave axial del oratorio (llamada en época cristiana Puerta de las Palmas), esta obra de consolidación de la fachada del patio se finalizó en $d \bar{u}$-l-hîŷya de 346/23 febrero - 23 marzo $958^{36}$. El despiece de los sillares de piedra de la fachada estuvo cubierto con estuco, como se puede ver en el dovelaje de los arcos que alternan las dovelas blancas con las rojas de tono almagra. Buena solución ornamental es la que aparece sobre las pilastras entre los arcos, a base de rectángulos concéntricos verticales delimitados por dos cenefas paralelas lisas ${ }^{37}$; el campo rectangular hubo de estar decorado con ornamento de estuco, quizá con tema de lazo o bien de sillares contrapeados fingidos. El arco de la Puerta de las Palmas y el abovedamiento tras él ha sido limpiado en 1999-2000, y los motivos geométricos de sus dovelas entrantes - a base de cuadraditos de una retícula en disposición diversa - radicalmente restaurados en almagra sobre fondo blanco tostädo.

${ }^{35}$ F. HeRnÁndez Giménez, El codo, fig. 9, que es la que yo también reproduzco aquí.

36 E. LÉvi-Provencal, Inscriptions, p. 8.

37 F. Hernández Giménez, El alminar de Abd al-Rahman III en la mezquita mayor de Córdoba, Patronato de la Alhambra, Granada 1975 , p. 271 , fig. 57 , la cual aparece numerada erróneamente en el texto como 58 y también a pie de página de la ilustración con el número 56, cuyo pie de figura dice: «Mezquita Mayor de Córdoba, hastial del oratorio sobre el Patio: restauración esquemática del decorado obra de $958 »$. 
Tras el refuerzo de la fachada del oratorio hacia el patio, la disposición de los pilares en T con columna exenta unida a los brazos y prolongación de la misma se vió afectada y cambiada (fig. 9). Los pilares tomaron planta rectangular, con saliente hacia el oratorio y su correspondiente columna adosada al mismo, mientras que en el intradós el refuerzo del siglo x se empotraron sus columnas en las pilastras y quedaron formadas unas mochetas en el intradós (fig. 9).

\section{La ampliación de la mezquita de al-Hakam II}

Según Ibn 'Iḍārī al-Marrākuš̄̄, la ampliación se inició por orden escrita de puño y letra del

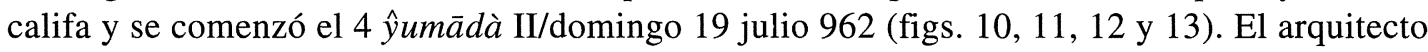
y su equipo, al ver la proximidad del río y el puente y al tener que resolver el gran desnivel del terreno, no tuvieron más remedio que reducir el sistema proporcional usado ${ }^{38}$. Lo hicieron de modo muy sencillo: tomaron el ancho de la mezquita (que hasta ahora había sido el lado unidad $(=1)$ de los rectángulos $\sqrt{ } 2 \mathrm{y} \sqrt{ } 3$ ), como lado longitudinal de un rectángulo $\sqrt{3}$ en escala proporcional menor. Para conseguirlo bastó con aplicar el ángulo de $300^{\circ}$ del cartabón desde las esquinas de los contrafuertes de los extremos de la qibla de 'Abd al-Raḥmān II y prolongar las líneas diagonales hasta donde se cruzan con las prolongaciones lineales rectas de los muros E. y O. Así se formó la nueva ampliación con planta de rectángulo $\sqrt{3}$, aquel cuya diagonal lo divide en dos cartabones de $30 .^{\circ}, 60 .^{\circ}$ y $90 .^{\circ}$ unidos por su hipotenusa común; el cateto menor del cartabón es el lado unidad (=1), o sea, los lados E. y O. con las fachadas de la ampliación; el cateto mayor del cartabón es el muro exterior de la qibla y el de la cara meridional de los contrafuertes angulares del de la ampliación de 'Abd al-Raḥmān II (figs. 10, 12).

La ampliación de al-Ḥakam II se comunicó con la de 'Abd al-Raḥmān II al abrir el muro de la qibla del siglo ix para que las naves continuasen. En el grosor de los contrafuertes de las diez arquerías se voltearon dos arcos que apoyan en columnas con espacio de intradós entre ellas. Los dos arcos de la nave axial — situados en el grosor de los contrafuertes de la qibla del s. IX-, son de herradura peraltada y el meridional está trasdosado por uno de lóbulos. Dan paso a la qubba al-kubrà al-mujarrama, lucernario llamado hoy Capilla de la Virgen de Villaviciosa. Los dobles arcos de las dos naves colaterales a la axial son lobulados, y muestra el del lado O. (el de naciente está revestido por la decoración mudéjar), trasdós de arco de medio punto que sobresale algo del muro con dovelas alternas rojas almagra y blancas; los de las restantes naves laterales son de herradura peraltada.

Debido al desnivel del terreno por su pronunciada bajada hacia el río, se construyó bajo las arquerías unos buenos muros de sillares trabados a soga y tizón. Así mismo unos gruesos muros macizos soportan la qibla interior del oratorio y la aparente exterior, entre cuyo grosor con relleno de tierra apisonada se alberga en alzado el espacioso nicho octogonal del mị̣rāb, y la bayt al-māl (el tesoro) a E. y la parte del sābāt (el pasadizo) que quedaba dentro de la mezquita a $\mathrm{O}$. Una plataforma escalonada de sillares rodea como andén su fachada de poniente y está unida al muro perimetral $O{ }^{39}$.

Conviene que resalte la dificultad de cimentación, pues los contrafuertes de los lados E., S. y O. —así como parte del grosor del muro de poniente algo desviado-, se quedan al exterior del rectángulo proporcional.

Si nos fijamos en la cimentación del mị̧rāb de al-Ḥakam II (965) (figs. 10-13), nos da más luz sobre como pudo ser el que este califa demolió, de época de 'Abd al-Raḥmãn II (c. 845):

\footnotetext{
38 A. Fernández-Puertas, «Spain and North Africa», p. 104.

39 Pedro Marfil Ruiz me ha comunicado su idea de que la mid̄á' de poniente de época de al-Hakam II estuvo en parte bajo este andén, donde hay una cámara hueca hoy dia para servicios del templo, que toma luz de la calle por dos pequeños vanos rectangulares. La miḍa 'a de naciente seguía siendo la del emir Hišām I.
} 


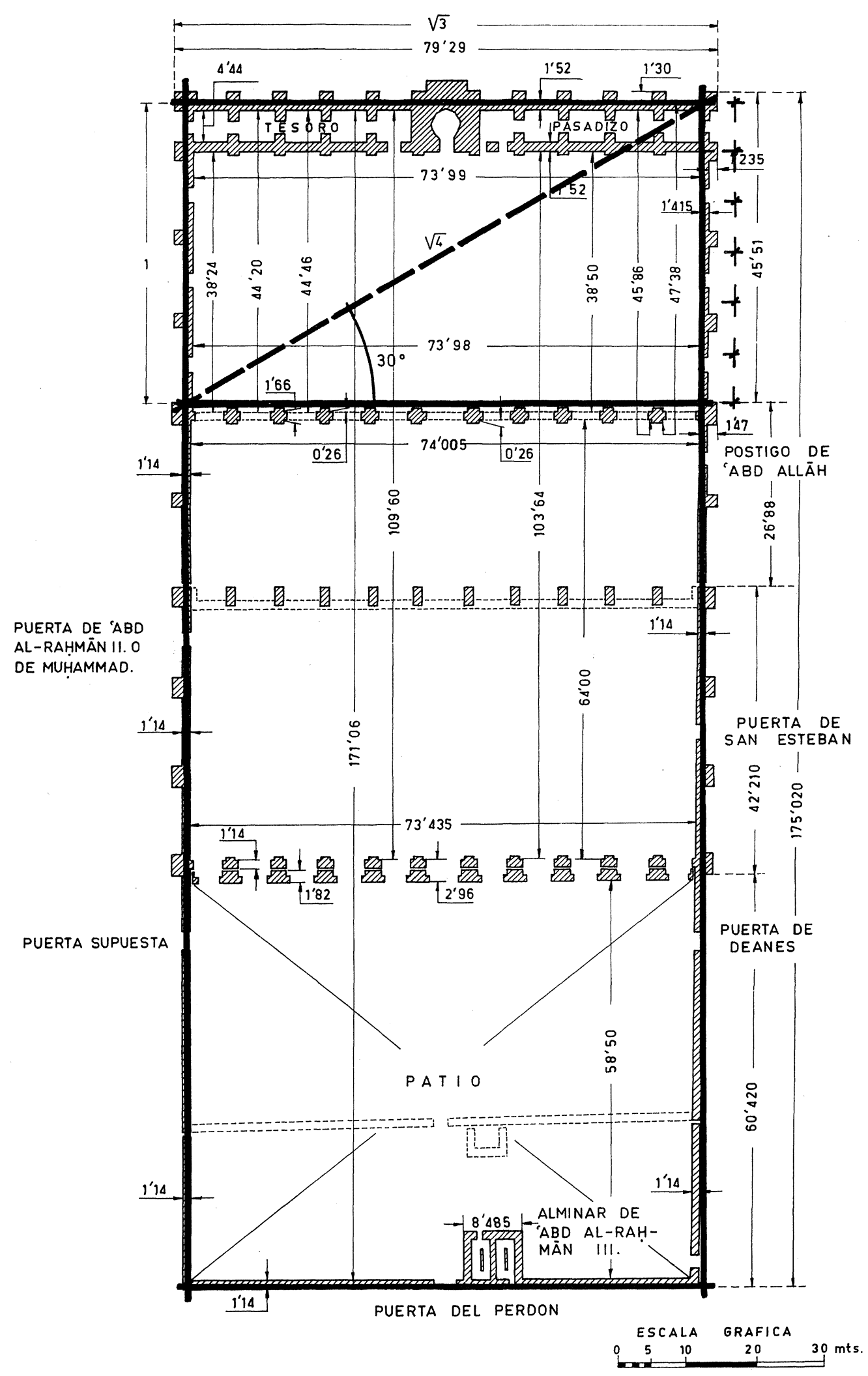

Fig. 10. 


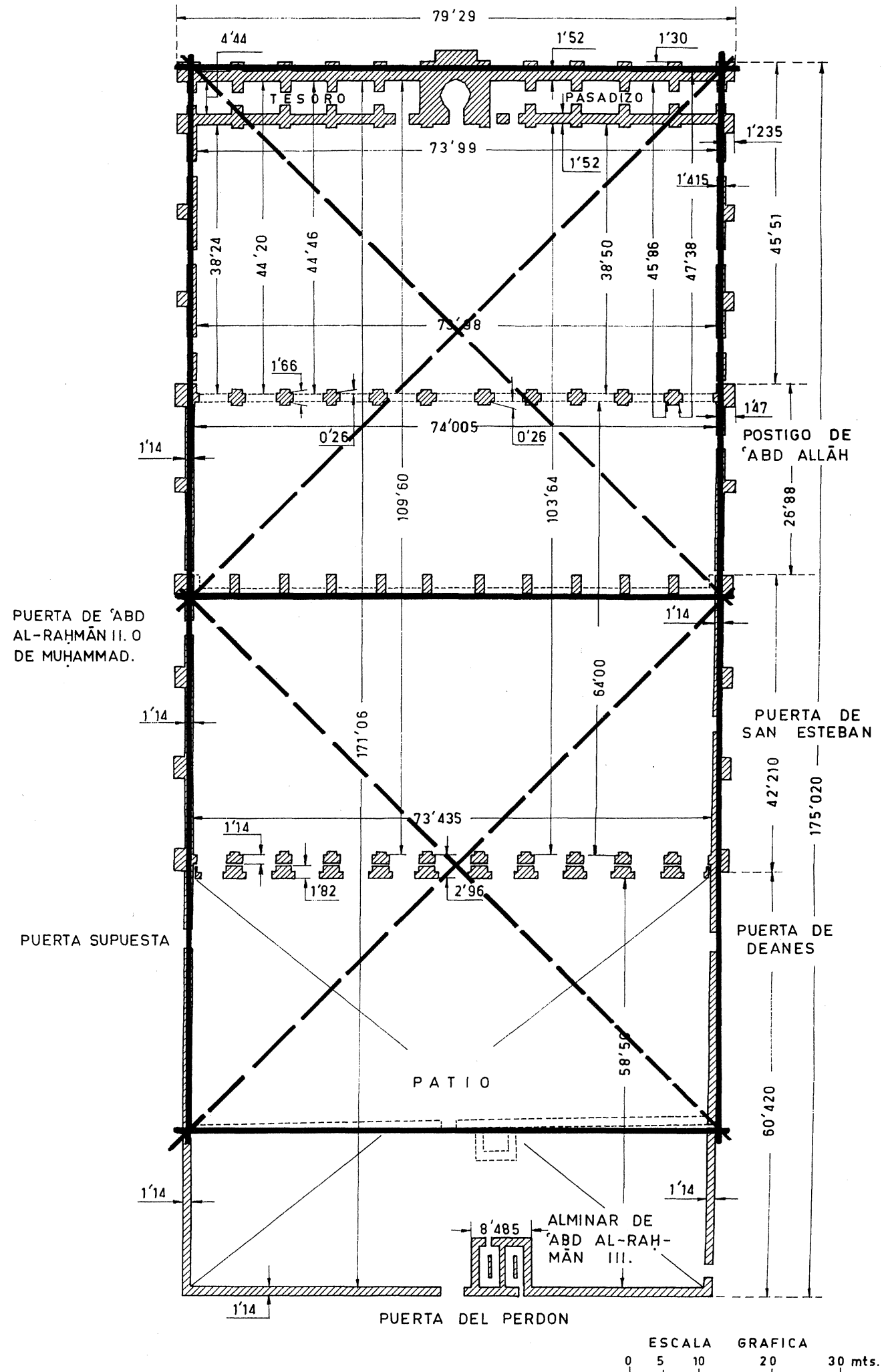

Fig. 11. 
1) Como el del siglo ix ocupa el grueso de la nave central axial, y la sobrepasa algo en sus lados E. y O. 2) Presenta también contrafuerte saliente escalonado como el del siglo Ix. 3) Se reutilizaron en el intradós del arco de herradura de acceso al mihrāa be al-Hakam, por expreso deseo del califa, los dos pares de columnas que con toda seguridad ocuparon análoga posición en el nicho que se demolió en el 965. 4) Carácter único en el mundo del Islam muestra el miḥrāab de alHakam II por su planta, por la disposición en diagonal de la misma, por la ornamentación, por su simbólica charnela que lo cubre como simbolo de agua de vida eterna ${ }^{40}$. 5) Así, pues, la cimentación del mị̂rāb del siglo Ix de 'Abd al-Raḥmān II es el prototipo del de al-Hakam II. Éste a su vez puede serlo del mihrāa $b$ con cámara poligonal de la mezquita almohade de Tinmal (11531154) en el Atlas, ubicado en una torre-contrafuerte que alberga también el alminar con las escaleras y una habitación alta bajo la azotea ${ }^{41}$. Es muy probable que esto se debe a que la bien orientada mezquita está en la ladera de la montaña, con su patio en la parte más elevada y el oratorio en la más inclinada. Quizás por esta disposición, el arquitecto almohade aprovechó como alminar la parte alta del gran contrafuerte de la cámara del mihrāab, con estancia y azotea por encima.

La disposición de las fachadas y los contrafuertes de los lados E. y O. de la ampliación de al-Hakam II, ha dependido de la profundidad dada al mihrā $b$ y a los tramos abovedados de la bayt al-māl y el sābāt (figs. 10, 11 y 12). Dos contrafuertes delimitaban la fachada de la bayt $a l-m \bar{a} l$, y otros lo hacen con el corredor del sāba ț en su desembocadura hacia la parte desaparecida que cruzaba sobre arcos al alcázar califal. En 1999-2000 los restos de este corredor en esta fachada han sido destruidos en buena parte, a pesar de la pronta diligencia de M. Nieto Cumplido y P. Marfil Ruiz, como indicaré al tratar de la ampliación de al-Hakam II en otro trabajo. El espacio que quedaba entre el más septentrional de los contrafuertes de la doble $q i$ bla de al-Ḥakam y los de la qibla de 'Abd al-Raḥmān II, se dividió en tres fachadas tripartitas separadas por dos contrafuertes que actuaban como fuelle de encaje para que las tres tuvieran prácticamente las mismas dimensiones (figs. 10, 11 y 12).

Al realizar Almanzor su ampliación, las tres fachadas del lado E. casi desaparecieron a causa de los arcos de herradura que se abrieron para poner en contacto su ampliación lateral naciente. Sin embargo, la fachada de la bayt al-māl se ha preservado mejor por haber quedado a los veintidos años, y hasta hoy, incorporada al interior del oratorio.

La mezquita de la ciudad de al-Zahrā' muestra $s \bar{a} b \bar{a} t$, que baja desde la terraza de al-Maŷlis al-Šarqī y cruza la calle mediante pasadizo sobre arcos, para ingresar en un corredor entre dos muros: el de la qibla exterior aparente y el de la qibla interior que soportaba el empuje de las arquerías; los contrafuertes de ambas no coinciden en medidas, y tampoco se alinean entre sí salvo en el nicho del mihrāb.

La ampliación de al-Hakam II en la mezquita de Córdoba muestra la doble qibla perfectamente alineados los contrafuertes y cámaras rectangulares entre ambas (figs. 10-13). En el muro hacia el interior del oratorio se encuentra la fachada del mihrāb y las colaterales de la bayt al-māl y el sābātt; el muro paralelo exterior del edificio con simetría en toda su disposición, presenta contrafuertes almenados, igual a torres militares, que daban una impresión de alta y sólida fortaleza inexpugnable a quien la contemplaba desde el lado S. y el extremo meridional del puente romano. Recuérdese que el nivel de la calle era bastante más bajo, como se ve en el nivel del suelo del arco triunfal de época de Felipe II (1575) situado en la desembocadura N. de este puente (figs. 10-13).

\footnotetext{
${ }^{40}$ A. FeRnÁNDEZ-Puertas, «Introducción», pp. XXXIV-XXXV.

${ }^{41}$ Christian Ewert y Jens-Peter Wisshak, Forschungen zur almohadischen Moschee, Lieferung 2: Die Moschee von Tinmal (Marokko). Mit einem Beitrag von Manuel Ocaña Jiménez. 1984. Madrider Beitrage, band 10. Deutsches Archäologisches Institut. Madrid. Verlag Philipp von Zabern. Mainz am Rhein. Text und Tafeln, pp. 16-19, figs. 4 y 5 en pp. 6 y 7 , láms. 1, 4, 6-9. Beilagen, 19.
} 


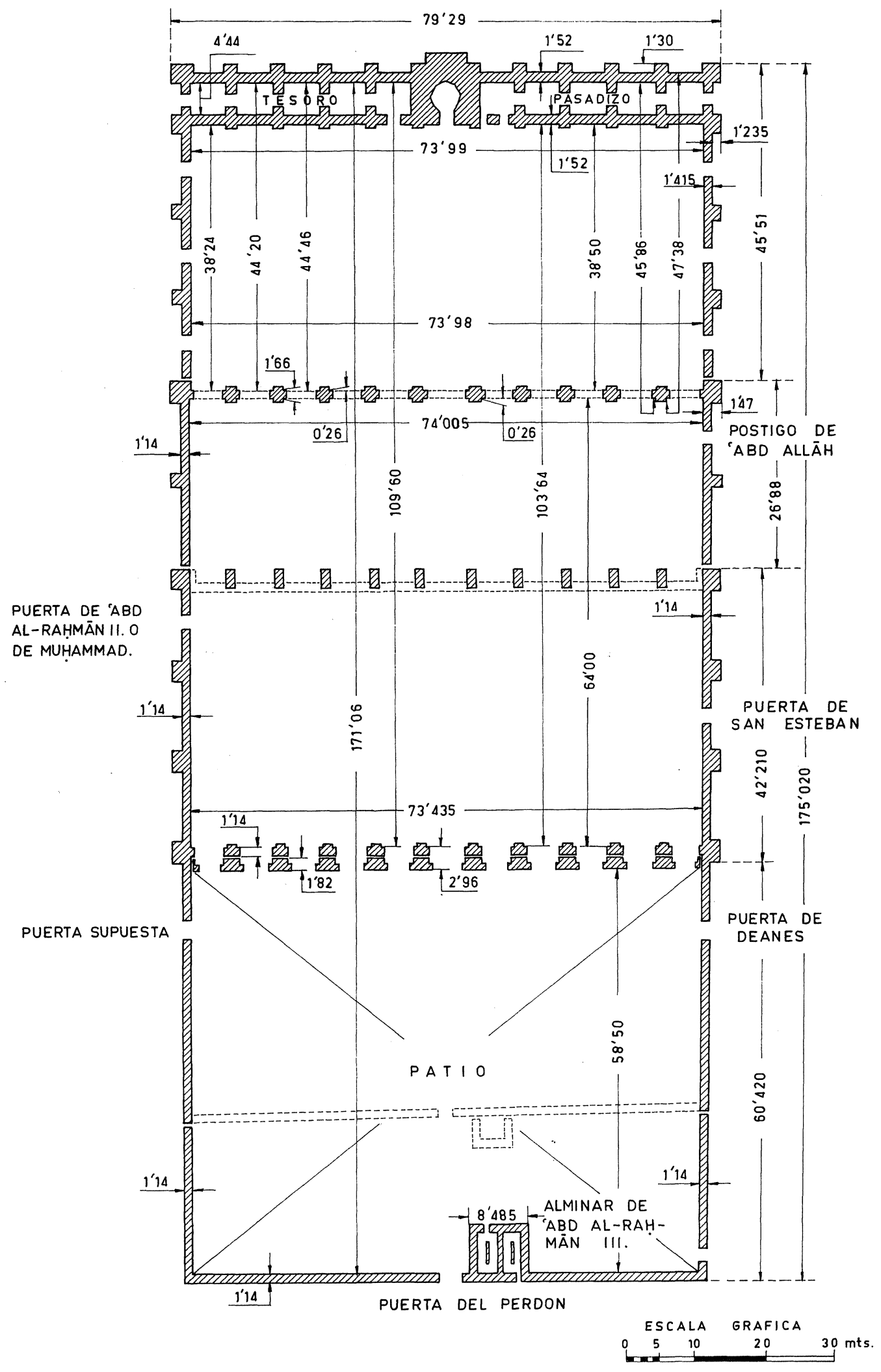

Fig. 12. 


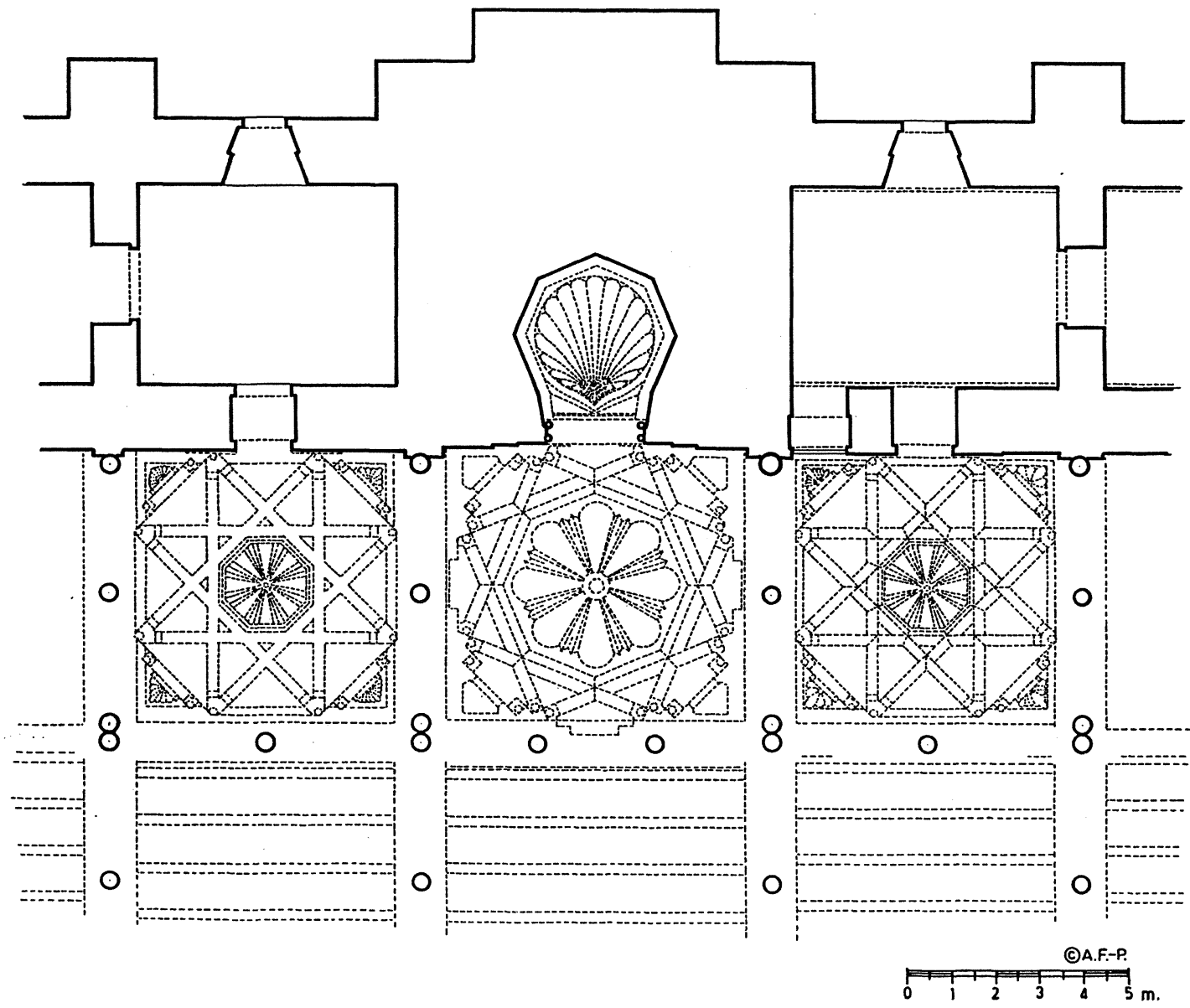

Fig. 13.

En el eje entre los muros interior y exterior de la qibla se ubicó el nicho octogonal del mihrāa y a cada lado cinco tramos idénticos, con bóvedas de cañón en sentido transversal a las naves con las que se corresponden. En planta alta muestra once tramos que se comunican entre sí con bóvedas esquifadas; el central (el sexto desde cada extremo), es más amplio que los otros diez, y el nivel más elevado de su suelo se salva por altos escalones a E. y O. Todos los tramos laterales al del mihrāb ofrecían ventanas en el piso alto, con celosías hacia el oratorio para que las mujeres y niños de la familia califal asistieran a las oraciones de la mezquita con plena seguridad y separación del resto de los fieles. Hoy están abiertas las ventanas sobre las puertas de la bayt al-māl y el sābāt, así como la del extremo E. que se usa como puerta de las estancias extremas de naciente, a las que se accede por escaleras de madera desde el suelo del santuario, hechas hace dos o tres años. El resto de las ventanas de los tramos altos están cegadas y sus paramentos los cubren grandes cuadros, como ha comprobado P. Marfil Ruiz en 1999. En el vano de ventana del tramo alto más al O. se ubicó una caja de seguridad. Quizá a dos de estos vanos, abiertos hacia la mezquita, pudieran corresponder las dos celosías de mármol que se conservan en el Museo Arqueológico Provincial de Córdoba ${ }^{42}$. Los diez tramos laterales - cinco a cada lado del mi hrā $b$ - muestran en su lado meridional hacia el río unas ventanas rectangulares con celosías de mármol y hojas chapadas de latón dorado.

${ }^{42}$ Varios, Al-Andalus. Las artes islámicas en España. The Metropolitan Museum of Art. Ediciones El Viso. Madrid 1992. François-Auguste de Montêquin, objetos 42a, b, «Dos celosías», pp. 252-254. 
La planta en $T$. - He tratado sobre la planta en T que presenta esta ampliación de al-Hakam II con la disposición de las qubbas lucernarias (fig. 16) ${ }^{43}$ : la de planta rectangular que se contruyó, en parte, sobre el lugar que había ocupado el mihrā b y su contrafuerte escalonado exterior, llamada al-qubba al-kubrà al-mujarrama, hoy capilla de Villaviciosa, será el pie de la $\mathrm{T}^{44}$; y las otras tres en el brazo transversal: la qubba del tramo ante el mihrāb junta con las dos qubbas colaterales de los tramos ante la bayt al-māl y el sābāt (figs. 13, 16).

En planta también se ve la dicha disposición en T compuesta por la nave axial más ancha que las colaterales y la disposición de los arcos entrecruzados de las tres qubbas mencionadas que se continúan longitudinalmente a ambos lados con arcos apuntados de rollos y de herradura decorativos, los cuales atajan las restantes naves y dejan hasta la qibla interior los dos últimos arcos de las diez galerías de los doce que cada una tiene (fig. 16). Muestran que son decorativos estos arcos transversales a las naves de ambos lados las celosías caladas que presentan sus albanegas, o aun más, el arco del extremo O., de herradura el cual tiene su imposta de arranque encima del dintel de la puerta de la fachada más meridional hacia O. de la ampliación de al-Ḥakam. Esta disposición se ha conservado bien en las naves que van a parar al sābāt, mientras que sólo han pervivido en parte en el lado de la bayt al-māl, cuyo emplazamiento lo ocupa en dos tramos la gran capilla octogonal barroca de Santa Teresa.

Las cuatro qubbas lucernarias son uno de los elementos más notables de la ampliación, y tienen un carácter preeminente en la arquitectura musulmana por su genial composición aparente de bóvedas de cuatro pares de arcos que se entrecruzan y dejan libre el centro. La qubba, hoy llamada Capilla de la Virgen de Villaviciosa, muestra planta rectangular evidente a la vista, con su ancho igual al de la nave axial y longitud de tres tramos de arquería. Las otras tres qubbas lucernarias ante el tramo del mihrāb y sus colaterales son también de planta rectangular (fig. 13). Los lados longitudinales de las tres son sus respectivas fachadas en la qibla y sus arquerías entrecruzadas fronteras a N. y los lados E. y O. con dos arcos de profundidad son su ancho. Sin embargo, causan los tres lucernarios una sensación cuadrangular si se mira a las bóvedas, y otra distinta a modo de rectángulo de luz si se contemplan los tres desde eí acceso a la nave central tras pasar desde la al-qubba al-kubrà al-mujarrama.

En el tramo del sābāt (figs. 10-13), en el ángulo SE. se encuentra tapiado el hueco rectangular que albergó el maravilloso minbar de ebanistería de maderas finas, ${ }^{45}$ que se puede ver cuando se ingresa al primer tramo del corredor en el ángulo de la estancia, cegado del oratorio por un tabique a ras con la fachada del sāba $\bar{t}$, e incluso por el exterior con ornamentación de mosaico y ataurique, repuesta la primera por el organero Patricio Furriell Crespo entre 1815-1818 ${ }^{46}$.

La figura 11 que presento muestra el cuadrado original de la mezquita de 'Abd al-Raḥmān I (siglo viII) con sus diagonales trazadas. Adosado al mismo por el lado S. hay otro cuadrado que abarca las ampliaciones del oratorio por 'Abd al-Raḥmān II (siglo Ix), y la de al-Ḥakam II (siglo $\mathrm{x}$ ). Este doble cuadrado es igual a $\sqrt{ } 4(=2)$, pero sólo se da porque he ignorado la prolongación proporcional del patio por 'Abd al-Raḥmān III. Luego, hay que desechar este doble cuadrado del trazado general, y lo indico en caso de que alguien lo hallara y estimara otro procedimiento, sin seguir la cronología de la construcción de la mezquita y sus sucesivos pasos. Para no enrevesar el tema, diré sólo que el segundo cuadrado se ha originado al reducir el arquitecto de al-Ḥakam II el tamaño de la unidad en el módulo proporcional.

\footnotetext{
43 A. Fernández-Puertas, «Spain and North Africa», p. 109.

44 A. FernÁNDEZ-PuERTAS, «Introducción», p. XXXI, nota 7.

45 F. HeRnández GiménEz, «El alminar móvil del siglo x de la mezquita de Córdoba», en Al-Andalus, vol. XXIV, 1959, pp. 381-399, figs. 1-6.

${ }_{46}$ Nótese que las cámaras colaterales del mịnrāb de la bayt al-māl y del sābāṭ en las figuras 10, 11, 12, las ha esquematizado F. HeRnÁndez Giménez y las ha convertido en cuadradas en vez de en rectangulares. por haberle dado el mismo ancho de muro a los más gruesos de las qiblas y a los de sus compartimentaciones en tramos abovedados.
} 


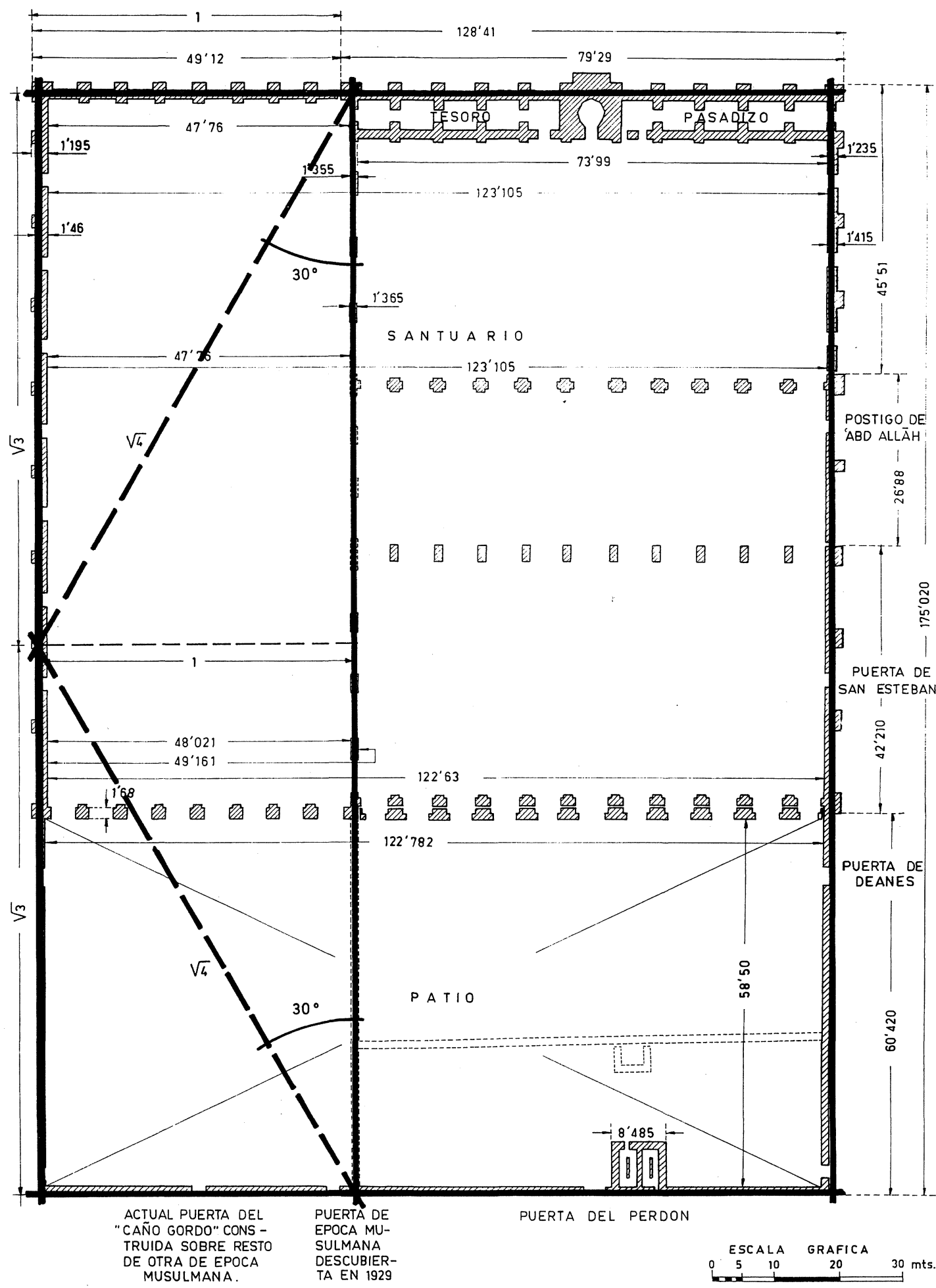

Fig. 14. 


\section{La ampliación de la mezquita por Almanzor}

En el 988 el ḥâŷyib del califa Hišām II, hijo de al-Ḥakam II, comenzó la última y más grande ampliación de la mezquita. Como no podía realizarla materialmente en sentido N.-S., ni tampoco hacia el costado O., donde se encuentra, aún hoy día, parte del recinto del alcázar emiro-califal, la hizo en todo el lado E. de la mezquita, tanto en el santuario como en el patio, dejando una calle a naciente, al otro lado de la cual edificó una midă', que se ha conocido en tiempo cristiano como el «Lavatorio de la Alcaicería» sin sospechar de que era el lugar del pabellón de abluciones y que su nombre era traducción del vocablo árabe ${ }^{47}$. Así, pues, tenía fija una de las medidas para su ampliación, la longitud, pero faltaba hallar la anchura que se le iba a dar a tan gran ampliación (fig. 14). El arquitecto logró la anchura aplicando el cartabón a ambos extremos N. y S. del lado longitudinal E.; trazó los correspondientes ángulos de $30 .^{\circ}$, prolongó las diagonales y donde ambas se juntan estableció el punto para trazar el nuevo testero en sentido E. y O. Luego, la parte añadida son dos rectángulos $\sqrt{ } 3$ (figs. $14,15,16$ ).

La ampliación de Almanzor respetó al máximo todo el edificio preexistente, pero tuvo que suprimir la fachada de 'Abd al-Raḥmān II, o Muhammad I, y las tres de al-Ḥakam II que daban acceso al oratorio y sus contrafuertes, aunque no tocó la fachada de la bayt al-māl. Tuvo que demoler la galería E. del patio e imitar las arquerías de las galerías de 'Abd alRaḥmān III. Las excavaciones realizadas por F. Hernández Giménez en 1931-1932 en la primera nave adosada de Almanzor dejaron visibles la miḍa' de Hišām I del siglo viII, la puerta practicada en el siglo IX a la mezquita con escalera de doble acceso, y la calzada de época de al-Hakam II ${ }^{48}$.

Esta ampliación de Almanzor presenta qibla sencilla cuyo muro interior es el mismo que el exterior y que tiene ocho contrafuertes con el angular, y entre ellos ocho tramos, el primero delimitado a O. por el contrafuerte de esquina de la qibla exterior de al-Ḥakam II. En el testero E. se construyeron siete fachadas con acceso directo al santuario, y - como en la ampliación de al-Hakam II-, con un ancho andén macizo de sillares que sube de altura conforme la calle desciende. Al patio se abrió una puerta (la llamada de Santa Catalina) simétrica a la puerta de los Deanes (figs. 14, 15, 16).

En el muro N. F. Hernández Giménez descubrió en 1929 una puerta relativamente pequeña, próxima al muro de época de 'Abd al-Raḥmān III como muestra el despiezo de los sillares, que las mujeres utilizaban para ingresar desde la calle a la galería $N$. También supone F. Hernández Giménez que la actual puerta llamada del «Caño Gordo» se edificó sobre resto de otra de época musulmana (figs. 14, 15, 16).

La ampliación de la sala de oraciones la puso en comunicación con la mezquita de 'Abd al-Rahmmān I (785) mediante 4 grandes arcos de lóbulos o rollos dispuestos de modo alterno de N. a S. (figs. 14, 15, 16). Es de suponer por la longitud del testero E de la ampliación de 'Abd al-Raḥmān II en los 840 que los vanos fueron tres (figs. 14, 15, 16). Por último, cuatro grandes arcos de herradura se practicaron en el muro de época de al-Hakam II, destruyéndose las fachadas E. cuyos restos se ven hoy in situ al haber desenfoscado el muro.

47 Alberto J. Montejo CóRdoba, «El pabellón de abluciones oriental de la mezquita aljama de Córdoba correspondiente a la ampliación de Almanzor», en Cuadernos de Madinat al-Zahrā', vol. 4, Consejería de Cultura, Junta de Andalucía, Córdoba, 1999, pp. 209-231, figs. 1-4, láms. 1-10. En el lado O. de la mezquita Almanzor edificó otra gran miḍā' en el solar que ahora ocupa el Palacio de Congresos, anterior Hospital de San Sebastián. Se le llamó también por su uso con la expresión de «Lavatorio de Cárdenas», sin que tampoco se sospechara que la palabra «lavatorio» era la traducción literal del término mida ă'. En este lugar se encontró la gran pila de abluciones troncocónica invertida de mármol blanco, que se colocó sobre el cancel visigodo, hasta que en los 1990 se han expuesto ambas piezas en vitrinas en dos zonas que el Cabildo ha adaptado como museo-histórico de la mezquita-catedral.

48 F. Hernández Giménez, El codo, p. 16, nota 1. 


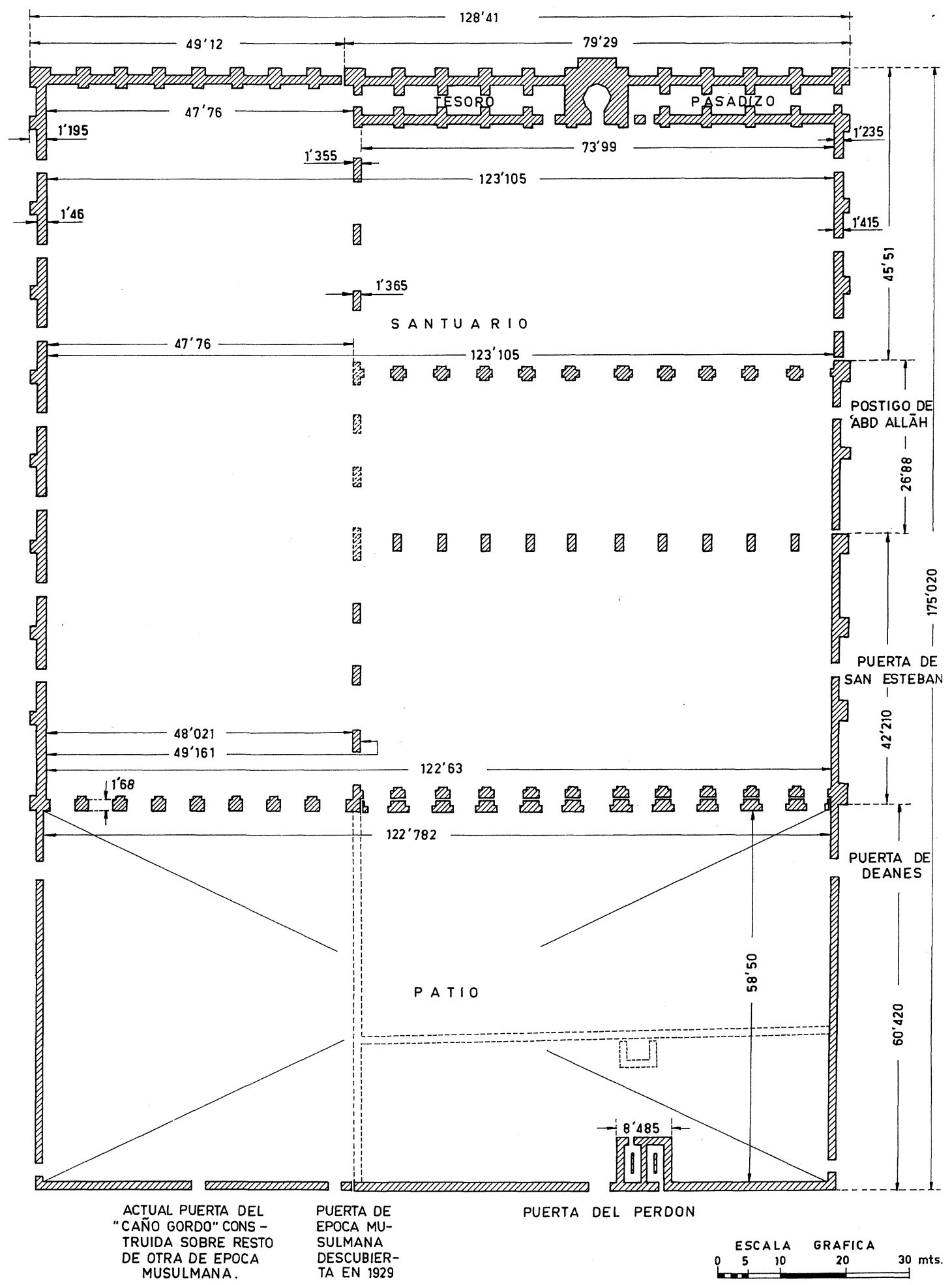

Fig. 15. 


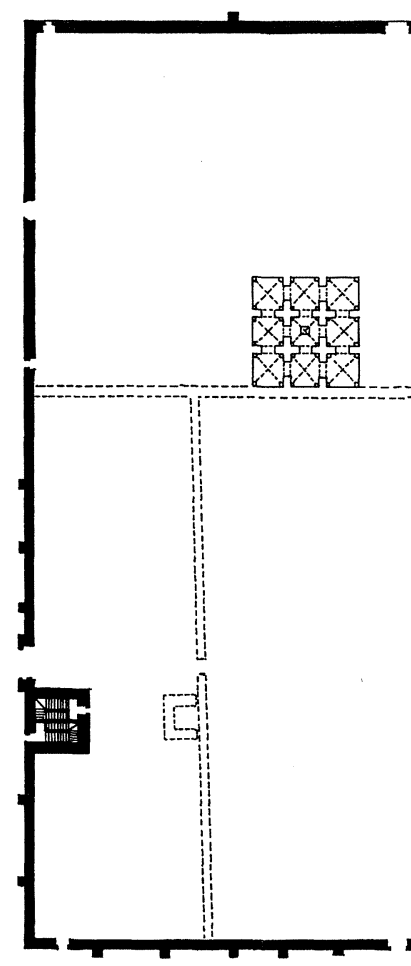

MEZOUITA DE CORDOBA RESTITUCION CON SUS AMPLIACIONES
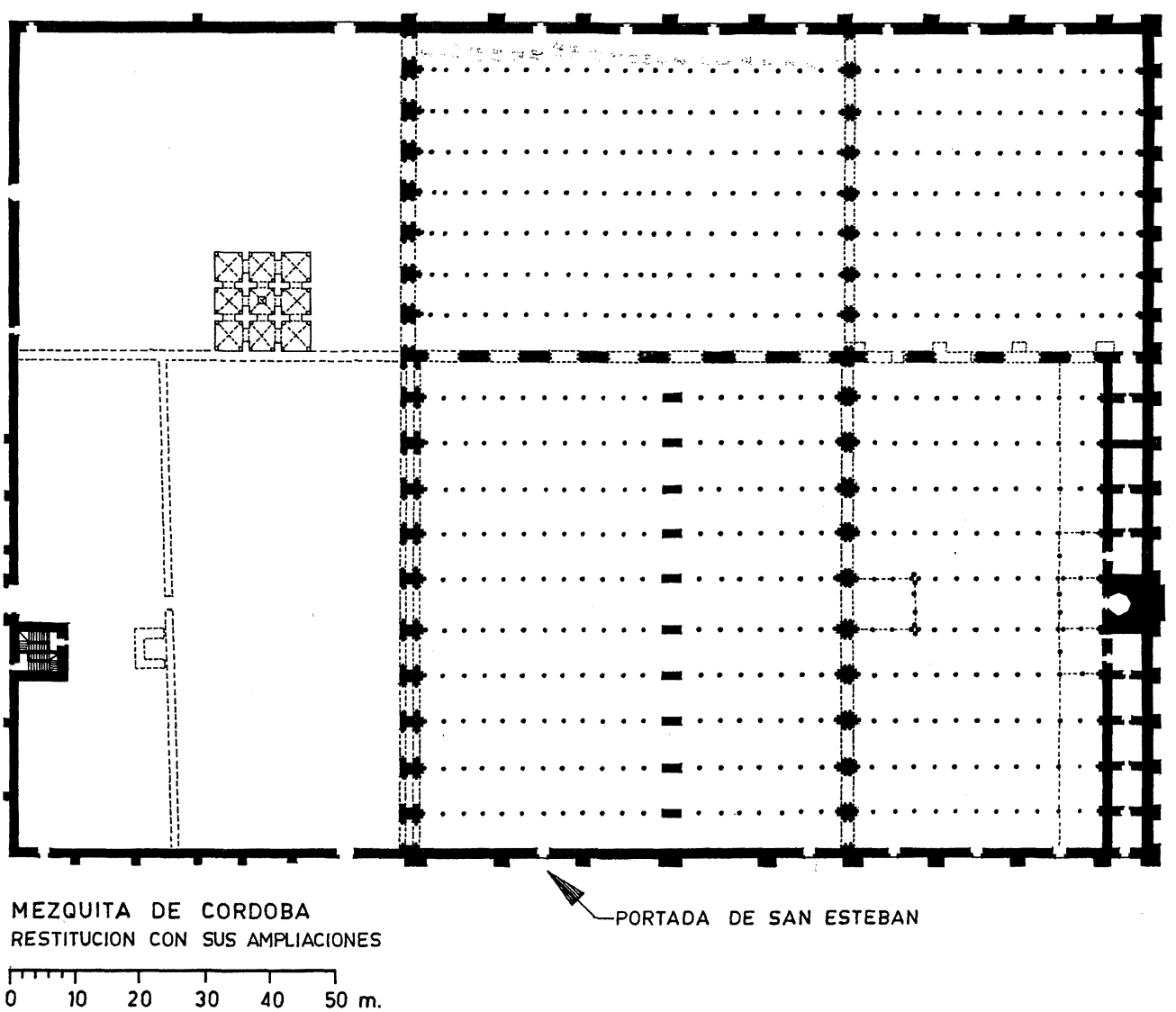

중

$\otimes$

$\otimes$

$\otimes$

ख

$\otimes$

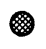
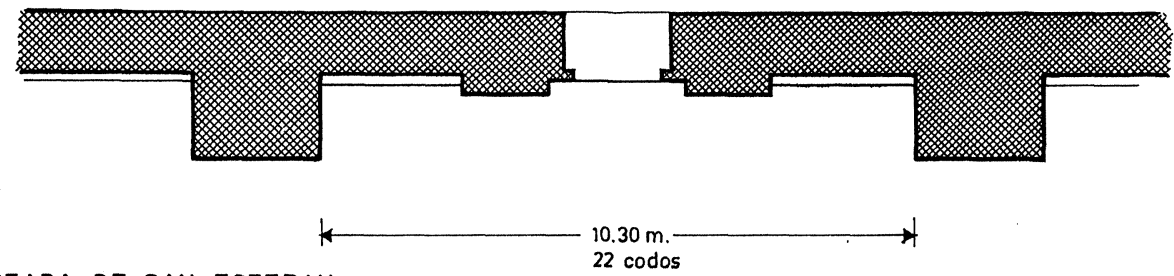

PORTADA DE SAN ESTEBAN

PLANTA (DETALLE)

$\begin{array}{llllll}1 & 1 & 1 & 1 & \\ 0 & 1 & 2 & 3 & 4 & \end{array}$

Fig. 16. 
La grandiosa ampliación de Almanzor presenta tres características arquitectónicas: 1) Sus arcos de la fachada N. al patio no tienen los refuerzos que 'Abd al-Raḥmān III adosó en el 958 a la primitiva fachada del siglo VIII. 2) Tampoco tiene los contrafuertes rectangulares de la qibla de la mezquita de 'Abd al-Raḥmān I, que se conservaron por necesidad en el interior del oratorio al hacerse la ampliación de 'Abd al-Rạ̣mān II. 3) Sólo muestra una qibla, la exterior, en vez de la doble edificada por al-Hakam II.

Debido a estos tres factores, y para conservar a la vista el máximo alineamiento interior de columnas y arcos en sentido E.-O., se introdujo en las siete arquerías que delimitan las ocho naves de la ampliación de Almanzor, y como elemento nuevo que corrigiera los delineamientos, cinco arcos de menor luz pentalobulados y de herradura apuntada, sobremontados en algún caso por otro de pequeño tímpano y herradura peraltada. Estos arcos de menor luz se hallan en dos sitios: junto a la fachada N. al patio, y por debajo de la línëa transversal de los contrafuertes de la qibla de 'Abd al-Raḥmān I:

1) Para compensar la diferencia de grosor de los pilares de los arcos de la fachada N. de esta ampliación con los bastante más gruesos del resto de la fachada (fig. 16), se colocaron como arranque dos arcos de menor luz en el primero y el segundo de las correspondientes siete arquerías. Tras éstos, siguen nueve arcos con el ancho y la alineación E.-O. normal de los de la mezquita del siglo viII.

2) Al llegar a los arcos número doce, trece y catorce en dirección a la qibla, éstos tres vuelven a ser de menor luz, análogos a los dos primeros próximos a la fachada N. Sirven para compensar los contrafuertes incorporados al oratorio de la qibla del siglo viII, pero aun así no coinciden con la línea de los contrafuertes, sino que se encuentran a un nivel justo antes de llegar a la cara norte de éstos.

No sé por qué no se situaron a eje con el macizo muro de estos contrafuertes, pues los efectos visuales lineales originales se perdieron en este sector con la construcción de la catedral. Sólo se han conservado estos tres arcos de menor luz — doce, trece y catorce- lobulados y de herradura apuntada, en las tres arquerías más a naciente, ya que la construcción de la cabecera rectangular de la catedral cristiana alteró este orden en las arquerías cuarta y quinta, y mutiló la sexta y séptima, las cuales fueron desmontadas y vueltas luego a levantar cuando se edificó la nave de la catedral.

F. Hernández Giménez dejó señalado con losas de mármol rectángulares la irregularidad de estos arcos de menor luz en las arquerías una, dos y tres de naciente; y marcó, en las arquerías cuarta, quinta, sexta y séptima, con losas cuadradas de mármol, el lugar que tuvieron las columnas en la ampliación de Almanzor antes de que éstas se desmontaran para construir la catedral. Así se había conservado de modo evidente el testimonio de su excavación. Sin embargo, en 1999, tras terminar la intervención arqueológica de la nave adosada a la primitiva mezquita, el arquitecto que mandó solar de nuevo este sector, no volvió a colocar dos de dichas losas de mármol por desconocimiento, razón por la cual el evidente testimonio arqueológico ha desaparecido.

Al llegar la ampliación de Almanzor a la línea de la qibla de 'Abd al-Rahmān II, construyó en esa zona unos contrafuertes — bastante similares a los que remodeló al-Ḥakam II al abrir la qibla del siglo IX - que apoyan en columnas adosadas, con dobles arcos de herradura transversales al sentido longitudinal de las naves (fig. 16). Desde estos contrafuertes continúan las siete arquerías con catorce arcos en dirección S.; y como esta parte del oratorio no tiene más que la qibla exterior, vienen a parar a ella los últimos arcos, apoyados en contrafuertes que sobresalen hacia el oratorio. 


\section{Conclusión}

(1) El arquitecto de la mezquita original de 'Abd al-Raḥmān I (785) concibió el edificio como un cuadrado que dividió por la mitad, y destinó la parte septentrional a patio y la meridional a santuario; dividió los lados E. y O. del santuario en tres partes iguales, situando la Bāb al-Uzarā' en el central del lado de poniente. (2) El arquitecto de 'Abd al-Raḥmān II en los 840 realizó la primera ampliación con planta de un rectángulo $\sqrt{ } 2$, es decir, tomó el lado del cuadrado, con el valor convencional de la unidad $(=1)$, como lado menor del rectángulo, y como lado mayor de éste la magnitud de la diagonal del cuadrado de la planta del siglo viII. (3) La tercera ampliación, llevada a cabo por el califa 'Abd al-Raḥmān III a mediados del siglo x, consistió en prolongar el patio original hacia N., para lo que abatió longitudinalmente la diagonal de la planta rectángulo $\sqrt{2}$, y formó así un rectángulo $\sqrt{3}$. (4) La cuarta ampliación la realizó al-Ḥakam II al prolongar la sala de oraciones en los 960 hacia S., para lo cual su equipo técnico arquitectónico redujo en escala el sistema proporcional, y trazó una planta rectángulo $\sqrt{3}$ mediante el uso del ángulo de $300^{\circ}$ del cartabón; así resultó que el ancho del oratorio - que hasta ahora había sido el lado unidad $(=1)$ del trazado porporcional - tomó el valor de $\sqrt{2}$, o cateto mayor del cartabón, y el nuevo lado unidad (=1) era el cateto menor de este triángulo (fig. 1). (5) La última ampliación la realizó el haŷyib Almanzor (988) adosada al testero E. de toda la mezquita para lo que el equipo técnico arquitectónico volvió a trazar dos rectángulos $\sqrt{3}$ al aplicar el ángulo de $30 .^{\circ}$ del cartabón en los extremos SE. y NE. del edificio preexistente.

Es asombroso que se haya aplicado el sistema proporcional pitagórico desde el principio hasta el final (siglos VIII, IX, X), con tal destreza y maestría como muestra el sistema bajo alHakam II ante la imposibilidad de seguir hacia S. y porque la mezquita hubiera resultado demasiado larga para el ancho que tiene. 